\title{
Disaster Risk and Business Cycles
}

\author{
François Gourio*
}

June 2009

\begin{abstract}
In order to develop a model that fits both business cycles and asset pricing facts, this paper introduces a small, time-varying risk of economic disaster in an otherwise standard real business cycle model. This simple feature can generate large and volatile risk premia. The paper establishes two simple theoretical results: first, under some conditions, when the probability of disaster is constant, the risk of disaster does not affect the path of macroeconomic aggregates - a "separation theorem" between quantities and asset prices in the spirit of Tallarini (2000). Second, shocks to the probability of disaster, which generate variation in risk premia over time, are observationaly equivalent to preference shocks. These shocks have a significant effect on macroeconomic aggregates: an increase in the perceived probability of disaster can lead to a collapse of investment and a recession, with no current or future change in productivity. This model thus allows analyzing the effect of a shock to "risk aversion" or a "shock to beliefs" on the macroeconomy (e.g. Fall 2008), and generates endogenously a correlation between output and asset prices or risk premia.
\end{abstract}

Keywords: business cycles, equity premium, term premium, return predictability, disasters, rare events, jumps.

JEL code: E32, E44, G12.

\section{Introduction}

The empirical finance literature has provided substantial evidence that risk premia are time-varying (see for instance Campbell and Shiller (1988), Fama and French (1989), Ferson and Harvey (1991), Cochrane (2005)). Yet, standard business cycle models such as the real business cycle model, or the DSGE models used for monetary policy analysis, largely fail to replicate the level, the volatility, and the cyclicality of risk premia. This seems an important neglect, since empirical work suggests a tight connection between risk premia and economic activity. For instance, Philippon (2008) and Gilchrist and Zakrajsek (2007) show that corporate bonds spreads are highly correlated with real physical investment, both in the time

*Firt version: February 2009. Boston University, Department of Economics, 270 Bay State Road, Boston MA 02215. Email: fgourio@bu.edu. Phone: (617) 792 2066. I thank participants in presentations at Boston University, Chicago BSB, FRB Dallas, Penn State, and Wharton for comments, and I thank Andrew Abel, Fernando Alvarez, Xavier Gabaix, Joao Gomes, Urban Jermann, Lars Hansen, Alex Monge, Erwan Quintin, Adrien Verdelhan, Jessica Wachter, and Amir Yaron for helpful discussions. This paper was first circulated under the title "Time-varying risk premia, time-varying risk of disaster, and macroeconomic dynamics." Some analytical results in this paper were independently obtained by Gabaix (2009). 
series and in the cross-section. A large research, summarized in Backus, Routledge and Zin (2008), shows that the stock market, the term premium, and (negatively) the short rate all lead the business cycle. $^{1}$

I introduce time-varying risk premia in a standard business cycle model, through a small, stochastically time-varying risk of economic "disaster", following the work of Rietz (1988), Barro (2006), and Gabaix (2007). Existing work has so far been confined to endowment economies, and hence does not consider the feedback from time-varying risk premia to macroeconomic activity. I prove two theoretical results, which hold under the assumption that a disaster reduces total factor productivity (TFP) and the capital stock by the same amount. First, when the risk of disaster is constant, the path for macroeconomic quantities implied by the model is the same as that implied by a model with no disasters, but a different discount factor $\beta$. This "observational equivalence" (in a sample without disasters) is similar to Tallarini (2000): macroeconomic dynamics are essentially unaffected by the amount of risk or the degree of risk aversion. Second, when the risk of disaster is time-varying, an increase in probability of disaster is observationally equivalent to a preference shock. This is interesting since these shocks appear to be important in accounting for the data, according to estimation of DSGE models with multiple shocks such as Smets and Wouters (2003). An increase in the perceived probability of disaster can create a collapse of investment and a recession, as risk premia rise, increasing the cost of capital. These business cycle dynamics occur with no change in current or future total factor productivity.

Quantitatively, I find that this model can match many asset pricing facts - the mean, volatility, and predictability of returns - while maintaining the basic success of the RBC model in accounting for quantities. This is important since many asset pricing models which are successful in endowment economies do not generalize well to production economies (as explained in Jermann (1998), Lettau and Uhlig (2001), Kaltenbrunner and Lochstoer (2008). This second shock also substantially increases the correlation between asset prices (or risk premia) and economic activity, making it closer to the data.

This risk of an economic disaster could be a strictly rational expectation, or more generally it could reflect a time-varying belief, which may differ from the objective probability - i.e., waves of optimism or pessimism (Jouini and Napp (2008)). For instance, during the recent financial crisis, many commentators have highlighted the possibility that the U.S. economy could fall into another Great Depression. Even well-known academic macroeconomists emphasized this. ${ }^{2}$ My model studies the macroeconomic effect of such time-varying beliefs. ${ }^{3}$ This simple modeling device captures the idea that aggregate uncertainty is sometimes high, i.e. people sometimes worry about the possibility of a deep recession. It also captures

\footnotetext{
${ }^{1}$ Schwert (1989) and Bloom (2008) also show that stock market volatility negatively leads economic activity.

2 Greg Mankiw (NYT, Oct 25, 2008): "Looking back at [the great Depression], it's hard to avoid seeing parallels to the current situation. (...) Like Mr. Blanchard at the I.M.F., I am not predicting another Great Depression. But you should take that economic forecast, like all others, with more than a single grain of salt."

Robert Barro (WSJ, March 4, 2009): “... there is ample reason to worry about slipping into a depression. There is a roughly one-in-five chance that U.S. GDP and consumption will fall by $10 \%$ or more, something not seen since the early 1930 s."

Krugman (NYT, Jan 4, 2009): "This looks an awful lot like the beginning of a second Great Depression."

${ }^{3}$ Of course in reality this change in probability of disaster may be an endogenous variable and not an exogenous shock. But it is useful to understand the effect of an increase in aggregate risk premia on the macroeconomy.
} 
the idea that there are some asset price changes which are not obviously related to current or future TFP, i.e. "bubbles" and "crashes", and which in turn affect the macroeconomy.

Introducing time-varying risk premia requires solving a model using nonlinear methods, i.e. going beyond the first-order approximation and considering "higher order terms". Researchers disagree on the importance of these higher order terms, and a fairly common view is that they are irrelevant for macroeconomic quantities. Lucas (2003) summarizes: "Tallarini uses preferences of the Epstein-Zin type, with an intertemporal substitution elasticity of one, to construct a real business cycle model of the U.S. economy. He finds an astonishing separation of quantity and asset price determination: The behavior of aggregate quantities depends hardly at all on attitudes toward risk, so the coefficient of risk aversion is left free to account for the equity premium perfectly." 4 My results show, however, that these higher-order terms can have a significant effect on macroeconomic dynamics, when we consider shocks to the probability of disaster. ${ }^{5}$

The paper is organized as follows: the rest of the introduction reviews the literature. Section 2 studies a simple analytical example in an AK model which can be solved in closed form and yields the central intuition for the results. Section 3 gives the setup of the full model and presents some analytical results. Section 4 studies the quantitative implications of the model numerically. Section 5 considers some extensions of the baseline model.

\section{Literature Review}

Gabaix (2009) independently obtained some related results in contemporaneous work. His study has more analytical results, including some interesting examples where fluctuations in risk premia have no macroeconomic consequences. My paper has a more quantitative focus, using Epstein-Zin utility, and focuses on the traditional RBC setup, where a shock to the probability of disaster is equivalent to a preference shock.

This paper is mostly related to three strands of literature. First, a large literature in finance builds and estimates models which attempt to match not only the equity premium and the risk-free rate, but also the predictability of returns and potentially the term structure. Two prominent examples are Bansal and Yaron (2004) and Campbell and Cochrane (1999). However, this literature is limited to endowment economies, and hence is of limited use to analyze the business cycle or to study policy questions.

Second, a smaller literature studies business cycle models (i.e. they endogenize consumption, investment and output), and attempts to match not only business cycle statistics but also asset returns first and second moments. My project is closely related to these papers (A non-exhaustive list would

\footnotetext{
${ }^{4}$ Note that Tallarini (2000) actually picks the risk aversion coefficient to match the Sharpe ratio of equity. Since return volatility is very low in his model - there are no capital adjustment costs - he misses the equity premium by several order of magnitudes.

${ }^{5}$ Cochrane (2005, p. 296-297) also discusses in detail the Tallarini (2000) result: "Tallarini explores a different possibility, one that I think we should keep in mind; that maybe the divorce between real business cycle macroeconomics and finance isn't that short-sighted after all (at least leaving out welfare questions, in which case models with identical dynamics can make wildly different predictions). (...) The Epstein-Zin preferences allow him to raise risk aversion while keeping intertemporal substitution constant. As he does so, he is better able to account for the market price of risk (...) but the quantity dynamics remain almost unchanged. In Tallarini's world, macroeconomists might well not have noticed the need for large risk aversion."
} 
include Jermann (1998), Tallarini (2000), Boldrin, Christiano and Fisher (2001), Lettau and Uhlig (2001), Kaltenbrunner and Lochstoer (2008), Campanele et al. (2008), Croce (2005), Gourio (2008c), Papanikolaou (2008), Kuehn (2008), Uhlig (2006), Jaccard (2008), Fernandez-Villaverde et al. (2008)). Most of these papers consider only the implications of productivity shocks, and generally study only the mean and standard deviations of return, and not the predictability of returns. Many of these papers abstract from hours variation. Several of these papers note that quantities dynamics are unaffected by risk aversion, ${ }^{6}$ hence it is sometimes said that asset prices can be discarded. The recent studies of Swanson and Rudebusch (2008a and 2008b) are exceptions on all these counts. The long-run target is to build a medium-scale DSGE model (as in Smets and Wouters (2003) or Christiano, Eichenbaum and Evans (2005)) that is roughly consistent with asset prices.

Finally, the paper draws from the recent literature on "disasters" or rare events (Rietz (1988), Barro (2006), Barro and Ursua (2008), Farhi and Gabaix (2008), Gabaix (2007), Gourio (2008a,2008b), Julliard and Ghosh (2008), Martin (2007), Santa Clara and Yan (2008), Wachter (2008), Weitzmann (2007)). Disasters are a powerful way to generate large risk premia. Moreover, as we will see, disasters are relatively easy to embed into a standard macroeconomic model.

There has been much interest lately in the evidence that the stock market leads TFP and GDP, which has motivated introducing "news shocks" (e.g., Beaudry and Portier (2006), Jaimovich and Rebelo (2008)), but my model suggests that this same evidence could also be rationalized by variations in risk premia due to changes in the probability of disasters.

Last, the paper has the same flavor as Bloom (2008) in that an increase in aggregate uncertainty creates a recession, but the mechanism and the focus (asset prices here) is different. Fernandez-Villaverde et al. (2009) also study the effect of shocks to risk in macro models, but they focus on open economy issues.

\section{A simple analytical example in an AK economy}

To highlight a key mechanism of the paper, consider a simple economy with a representative consumer who has power utility:

$$
V_{t}=E_{t} \sum_{t=0}^{\infty} \beta^{t} \frac{C_{t}^{1-\gamma}}{1-\gamma},
$$

where $C_{t}$ is consumption and $\gamma$ is the risk aversion coefficient (and also the inverse of the the intertemporal elasticity of substitution of consumption). This consumer operates an AK technology:

$$
Y_{t}=A_{t} K_{t}
$$

where $Y_{t}$ is output, $K_{t}$ is capital, and $A_{t}$ is a stochastic technology shock which is assumed to follow a stationary Markov process with transition $Q$ (for instance, an $\operatorname{AR}(1)$ process). The resource constraint is:

$$
C_{t}+I_{t} \leq A_{t} K_{t}
$$

\footnotetext{
${ }^{6}$ Fernandez-Villaverde et al. (2008) use perturbation methods and report that the first three terms, which are calculated symbolically by the computer, are independent of risk aversion (there is, of course, a steady-state adjustment).
} 
The economy is randomly hit by disasters. A disaster destroys a share $b_{k}$ of the capital stock. This could be due to a war which physically destroys capital, but there are alternative interpretations. For instance, $b_{k}$ could reflect expropriation of capital holders (if the capital is taken away and then not used as effectively), or it could be a "technological revolution" that makes a large share of the capital worthless; or finally it could be that even though physical capital is not literally destroyed, intangible capital (such as matches between firms, employees, and customers) are lost. The law of accumulation for capital is thus:

$$
\begin{aligned}
K_{t+1} & =(1-\delta) K_{t}+I_{t}, \text { if } x_{t+1}=0 \\
& =\left((1-\delta) K_{t}+I_{t}\right)\left(1-b_{k}\right), \text { if } x_{t+1}=1
\end{aligned}
$$

where $x_{t+1}$ is a binomial variable which is 1 with probability $p_{t}$ and 0 with probability $1-p_{t}$. The probability of disaster $p_{t}$ is assumed to vary over time, but to maintain tractability I assume in this section that it is i.i.d.: $p_{t}$, the probability of a disaster at time $t+1$, is drawn at time $t$ from a constant cumulative distribution function $F$. A disaster does not affect productivity $A_{t}$. I will relax this assumption in section $3 .^{7}$ Finally, I assume that the three random variables $p_{t+1}, A_{t+1}$, and $x_{t+1}$ are independent. The "normal shock" $A_{t}$ and the disaster are naturally independent, but the key assumption is that the occurrence of a disaster does not influence the probability of a disaster going forward. I also discuss this assumption in more detail in section 3 .

This model has one endogenous state $K$ and two exogenous states $A$ and $p$, and there is one control variable $C$. There are three shocks: "normal shocks" $A^{\prime}$, the realization of disaster $x^{\prime} \in\{0,1\}$, and the draw of a new probability of disaster $p^{\prime}$. The Bellman equation for the representative consumer is:

$$
\begin{aligned}
V(K, A, p) & =\max _{C, I}\left\{C^{1-\gamma}+\beta E_{p^{\prime}, x^{\prime}, A^{\prime}}\left(V\left(K^{\prime}, A^{\prime}, p^{\prime}\right)\right)\right\} \\
\text { s.t. } & : \\
C+I & \leq A K, \\
K^{\prime} & =((1-\delta) K+I)\left(1-x^{\prime} b_{k}\right) .
\end{aligned}
$$

At the risk of being pedantic, the conditional expectation can be written as:

$$
\begin{aligned}
& E_{p^{\prime}, x^{\prime}, A^{\prime}}\left(V\left(K^{\prime}, A^{\prime}, p^{\prime}\right)\right) \\
= & \iint\left(p V\left(((1-\delta) K+I)\left(1-b_{k}\right), A^{\prime}, p^{\prime}\right)+(1-p) V\left((1-\delta) K+I, A^{\prime}, p^{\prime}\right)\right) d Q\left(A^{\prime} \mid A\right) d F\left(p^{\prime}\right) .
\end{aligned}
$$

The assumptions made ensure that $V$ is homogeneous, i.e. we can guess and verify that $V$ is of the form $V(K, A, p)=K^{1-\gamma} g(A, p)$, where $g$ is defined through the Bellman equation:

$$
g(A, p)=\max _{i}\left\{\begin{array}{c}
(A-i)^{1-\gamma} \\
+\beta(1-\delta+i)^{1-\gamma}\left(1-p+p\left(1-b_{k}\right)^{1-\gamma}\right)\left(E_{p^{\prime}, A^{\prime}} g\left(A^{\prime}, p^{\prime}\right)\right)
\end{array}\right\},
$$

where $i=\frac{I}{K}$ is the investment rate. The first-order condition with respect to $i$ yields, after rearranging:

$$
\left(\frac{A-i}{1-\delta+i}\right)^{-\gamma}=\beta\left(1-p+p\left(1-b_{k}\right)^{1-\gamma}\right)\left(E_{p^{\prime}, A^{\prime}} g\left(A^{\prime}, p^{\prime}\right)\right)
$$

\footnotetext{
${ }^{7}$ In an AK model, a permanent reduction in productivity would lead to a permanent reduction in the growth rate of the economy, since permanent shocks to $A$ affect the growth rate of output permanently.
} 
Given that $p$ is i.i.d., the expectation of $g$ on the right-hand side is independent of the current $p$. The left-hand side is an increasing function of $i$. The term $\left(1-b_{k}\right)^{1-\gamma}$ is greater than unity if and only if $\gamma>1$. Hence, $i$ is increasing in $p$ if $\gamma>1$, it is decreasing in $p$ if $\gamma<1$, and it is independent of $p$ if $\gamma=1$.

The intuition for this result is as follows: if $p$ goes up, the expected risk-adjusted return on capital goes down, due to a higher risk of disaster. The effect of a change in the expected return on the consumptionsavings choice depends on the value of the IES, because of offsetting wealth and substitution effects. If the IES is unity (i.e. utility is log), savings are unchanged and thus the savings or investment rate does not respond to a change in the probability of disaster. But if the IES is larger than unity, i.e. $\gamma<1$, the substitution effect dominates, and $i$ is decreasing in $p$. Hence, an increase in the probability of disaster leads initially, in this model, to a decrease in investment, and an increase in consumption, since output is unchanged on impact. Next period, the decrease in investment leads to a decrease in the capital stock and hence in output. This simple analytical example thus shows that a change in the perceived probability of disaster can lead to a decline in investment and output. (Note that the argument has to do with the effect of higher uncertainty on the optimal savings decision.)

\section{Extension to Epstein-Zin preferences}

To illuminate the respective role of risk aversion and the intertemporal elasticity of substitution, it is useful to extend the preceding example to the case of Epstein-Zin utility. Assume, then, that the utility $V_{t}$ satisfies the recursion:

$$
V_{t}=\left((1-\beta) C_{t}^{1-\gamma}+\beta E_{t}\left(V_{t+1}^{1-\theta}\right)^{\frac{1-\gamma}{1-\theta}}\right)^{\frac{1}{1-\gamma}},
$$

where $\theta$ measures risk aversion towards static gambles, $\gamma$ is the inverse of the intertemporal elasticity of substitution (IES) and $\beta$ reflects time preference. It is straightforward to extend the results above; the first-order condition now reads

$$
\left(\frac{A-i}{1-\delta+i}\right)^{-\gamma}=\frac{\beta}{1-\beta}\left(1-p+p\left(1-b_{k}\right)^{1-\theta}\right)^{\frac{1-\gamma}{1-\theta}}\left(E_{p^{\prime}, A^{\prime}} g\left(A^{\prime}, p^{\prime}\right)^{\frac{1-\theta}{1-\gamma}}\right)^{\frac{1-\gamma}{1-\theta}}
$$

and we can apply the same argument as above, in the realistic case where $\theta \geq 1$ : the now risk-adjusted return on capital is $\left(1-p+p\left(1-b_{k}\right)^{1-\theta}\right)^{\frac{1}{1-\theta}}$; it falls as $p$ rises; an increase in the probability of disaster will hence reduce investment if and only if the IES is larger than unity. (As in Weil (1989), the riskadjusted return is $\left.E\left(R^{1-\theta}\right)^{\frac{1}{1-y}}\right){ }^{8}$ Hence, the parameter which determines the sign of the response is the IES, and the risk aversion coefficient (as long as it is greater than unity) determines the magnitude of the response only. While this example is revealing, ${ }^{9}$ it has a number of simplifying features, which lead us to turn now to a quantitative model.

\footnotetext{
${ }^{8}$ The disaster reduces the mean return itself, but this is actually not important; we could assume that there is a small probability of a "capital windfall" so that a change in $p$ does not affect the mean return on capital. Crucially, what matters here is the risk-adjusted return on capital, and a higher risk reduces this return.

${ }^{9}$ This example is related to work by Epaulard and Pommeret (2003), Jones, Manuelli and Siu (2005a, 2005b), and to the earlier work of Obstfeld (1994).
} 


\section{A Real Business Cycle model with time-varying probability of disasters}

This section introduces a real business cycle model with time-varying risk of disaster and study its implications, first analytically, and then numerically. This model extends the simple example of the previous section in the following dimensions: (a) the probability of disaster is persistent instead of i.i.d.; (b) the production function is neoclassical; (c) labor is elastically supplied; (d) disasters may affect total factor productivity as well as capital; (e) there are capital adjustment costs.

\subsection{Model Setup}

The representative consumer has preferences of the Epstein-Zin form, and the utility index incorporates hours worked $N_{t}$ as well as consumption $C_{t}$ :

$$
V_{t}=\left(u\left(C_{t}, N_{t}\right)^{1-\gamma}+\beta E_{t}\left(V_{t+1}^{1-\theta}\right)^{\frac{1-\gamma}{1-\theta}}\right)^{\frac{1}{1-\gamma}},
$$

where $^{10}$ the per period felicity function $u(C, N)$ is assumed to have the following form:

$$
u(C, N)=C^{v}(1-N)^{1-v} .
$$

There is a representative firm, which produces output using a standard Cobb-Douglas production function:

$$
Y_{t}=K_{t}^{\alpha}\left(z_{t} N_{t}\right)^{1-\alpha}
$$

where $z_{t}$ is total factor productivity (TFP), to be described below. The firm accumulates capital subject to adjustment costs:

$$
\begin{aligned}
K_{t+1} & =(1-\delta) K_{t}+\phi\left(\frac{I_{t}}{K_{t}}\right) K_{t}, \text { if } x_{t+1}=0, \\
& =\left((1-\delta) K_{t}+\phi\left(\frac{I_{t}}{K_{t}}\right) K_{t}\right)\left(1-b_{k}\right), \text { if } x_{t+1}=1,
\end{aligned}
$$

where $\phi$ is an increasing and concave function, which curvature captures adjustment costs, and $x_{t+1}$ is 1 if there is a disaster at time $t+1$ (with probability $p_{t}$ ) and 0 otherwise (probability $1-p_{t}$ ). In the quantitative section, we will consider various values for $b_{k}$, including possibly zero - i.e., a disaster only affects TFP. The resource constraint is

$$
C_{t}+I_{t} \leq Y_{t}
$$

Aggregate investment cannot be negative:

$$
I_{t} \geq 0 .
$$

Finally, we describe the shock processes. Total factor productivity is affected by the "normal shocks" $\varepsilon_{t}$ as well as the disasters. A disaster reduces TFP by a permanent amount $b_{t f p}$ :

$$
\begin{aligned}
\log z_{t+1} & =\log z_{t}+\mu+\sigma \varepsilon_{t+1}, \text { if } x_{t+1}=0, \\
& =\log z_{t}+\mu+\sigma \varepsilon_{t+1}+\log \left(1-b_{t f p}\right), \text { if } x_{t+1}=1,
\end{aligned}
$$

\footnotetext{
${ }^{10}$ Note that it is commonplace to have a $(1-\beta)$ factor in front of $u(C, N)$ in $(2)$, but this is merely a normalization, which it is useful to forgo in this case.
} 
where $\mu$ is the drift of TFP, and $\sigma$ is the standard deviation of "normal shocks". Here too, we will consider various values for $b_{t f p}$, including possibly zero - i.e., a disaster only destroys capital. Last, $p_{t}$ follows a stationary Markov process with transition function $Q$. In the quantitative application, we will simply assume that the $\log$ of $p_{t}$ follows an $\operatorname{AR}(1)$ process.

I assume that $p_{t+1}, \varepsilon_{t+1}$, and $x_{t+1}$ are independent conditional on $p_{t}$. This assumption requires that the occurrence of a disaster today does not affect the probability of a disaster tomorrow. This assumption could be wrong either way: a disaster today may indicate that the economy is entering a phase of low growth or is less resilient than thought, leading agents to revise upward the probability of disaster, following the occurrence of a disaster; but on the other hand, if a disaster occurred today, and capital or TFP fell by a large amount, it is unlikely that they will fall again by a large amount next year. Rather, historical evidence suggests that the economy is likely to grow above trend for a while (Gourio (2008a), Barro et al. (2009)). In section 5, I extend the model to consider these different scenarios.

\subsection{Bellman Equation}

This model has three states: capital $K$, technology $z$ and probability of disaster $p$; two independent controls: consumption $C$ and hours worked $N$; and three shocks: the realization of disaster $x^{\prime} \in\{0,1\}$, the draw of the new probability of disaster $p^{\prime}$, and the "normal shock" $\varepsilon^{\prime}$. Denote $V(K, z, p)$ the value function, and define $W(K, z, p)=V(K, z, p)^{1-\gamma}$. The social planning problem can be formulated as: ${ }^{11}$

$$
\begin{aligned}
W(K, z, p) & =\max _{C, I, N}\left\{\left(C^{v}(1-N)^{1-v}\right)^{1-\gamma}+\beta\left(E_{p^{\prime}, z^{\prime}, x^{\prime}} W\left(K^{\prime}, z^{\prime}, p^{\prime}\right)^{\frac{1-\theta}{1-\gamma}}\right)^{\frac{1-\gamma}{1-\theta}}\right\} \\
\text { s.t. } & : \\
C+I & \leq z^{1-\alpha} K^{\alpha} N^{1-\alpha} \\
K^{\prime} & =\left((1-\delta) K+\phi\left(\frac{I}{K}\right) K\right)\left(1-x^{\prime} b_{k}\right), \\
\log z^{\prime} & =\log z+\mu+\sigma \varepsilon^{\prime}+x^{\prime} \log \left(1-b_{t f p}\right) .
\end{aligned}
$$

A standard homogeneity argument implies that we can write $W(K, z, p)=z^{v(1-\gamma)} g(k, p)$, where $k=$ $K / z$, and $g$ satisfies the associated Bellman equation:

$$
\begin{aligned}
& g(k, p)=\max _{c, i, N}\left\{\begin{array}{c}
c^{v(1-\gamma)}(1-N)^{(1-v)(1-\gamma)} \\
+\beta e^{\mu v(1-\gamma)}\left(E_{p^{\prime}, \varepsilon^{\prime}, x^{\prime}} e^{\sigma \varepsilon^{\prime} v(1-\theta)}\left(1-x^{\prime}+x^{\prime}\left(1-b_{t f p}\right)^{v(1-\theta)}\right) g\left(k^{\prime}, p^{\prime}\right)^{\frac{1-\theta}{1-\gamma}}\right)^{\frac{1-\gamma}{1-\theta}}
\end{array}\right\} \\
& \text { s.t. : } \\
& c=k^{\alpha} N^{1-\alpha}-i, \\
& k^{\prime}=\frac{\left(1-x^{\prime} b_{k}\right)\left((1-\delta) k+\phi\left(\frac{i}{k}\right) k\right)}{e^{\mu+\sigma \varepsilon^{\prime}}\left(1-x^{\prime} b_{t f p}\right)} .
\end{aligned}
$$

Here $c=C / z$ and $i=I / z$ are consumption and investment detrended by the stochastic technology trend $z$. This simplification will lead to some analytical results, and can further be studied using standard numerical methods since $k$ is stationary. Note that $b_{t f p}$ is the amount by which $z$ falls, and TFP is actually $z^{1-\alpha}$, hence the decrease in TFP is smaller than the decrease in $z$.

\footnotetext{
${ }^{11}$ Because we take a power $1-\gamma$ of the value function, if $\gamma>1$, the max must be transformed into a min.
} 


\subsection{Asset Prices}

It is straightforward to compute asset prices in this economy. The stochastic discount factor is given by the formula

$$
M_{t, t+1}=\beta\left(\frac{C_{t+1}}{C_{t}}\right)^{v(1-\gamma)-1}\left(\frac{1-N_{t+1}}{1-N_{t}}\right)^{(1-v)(1-\gamma)}\left(\frac{V_{t+1}}{E_{t}\left(V_{t+1}^{1-\theta}\right)^{\frac{1}{1-\theta}}}\right)^{\gamma-\theta}
$$

The price of a purely risk-free asset is

$$
P_{r f, t}=E_{t}\left(M_{t, t+1}\right) \stackrel{\text { def }}{=} P_{r f}(k, p) .
$$

This risk-free asset may not have an observable counterpart. Following Barro (2006), I will assume that government bonds are not risk-free but are subject to default risk during disasters. ${ }^{12}$ More precisely, if there is a disaster, then with probability $q$ the bonds will default and the recovery rate will be $r$. The T-Bill price can then be easily computed as

$$
P_{1, t}=E_{t}\left(M_{t, t+1}\left(1-x_{t+1} q(1-r)\right)\right) \stackrel{\text { def }}{=} P_{1}(k, p)
$$

Computing the yield curve is conceptually easy using the standard recursion for zero-coupon bonds: ${ }^{13}$

$$
P_{n, t}=E_{t}\left(M_{t, t+1} P_{n-1, t+1}\left(1-x_{t+1} q(1-r)\right) \stackrel{\text { def }}{=} P_{n}(k, p) .\right.
$$

Here I assume that a disaster simply reduces the face value of the bond (and does not affect its maturity). The ex-dividend value of the firm assets $F_{t}$ is defined through the value recursion:

$$
F_{t}=E_{t}\left(M_{t, t+1}\left(D_{t+1}+F_{t+1}\right)\right)
$$

where $D_{t}=F\left(K_{t}, z_{t} N_{t}\right)-w_{t} N_{t}-I_{t}$ is the payout of the representative firm, and $w_{t}$ is the wage rate, given by the marginal rate of substitution of the representative consumer between consumption and leisure. If aggregate investment is positive, the firm value $F_{t}$ satisfies the $q$-theoretic relation:

$$
F_{t}=\frac{\left(1-p b_{k}\right) K_{t+1}}{\phi^{\prime}\left(\frac{I_{t}}{K_{t}}\right)}
$$

so that if we define Tobin's $q$ as $Q_{t}=\frac{F_{t}}{\left(1-p b_{k}\right) K_{t+1}}$, we have $Q_{t}=\phi^{\prime}\left(\frac{I_{t}}{K_{t}}\right)$, and $Q_{t}$ is one in the limiting case of no adjustment costs. (In the standard model, $p=0$, but here the amount of capital available tomorrow is unknown, since some capital may be destroyed if there is a disaster.) Finally, the equity return is obtained as

$$
R_{t, t+1}=\frac{D_{t+1}+F_{t+1}}{F_{t}}
$$

\footnotetext{
${ }^{12}$ Empirically, default often takes the form of high rates of inflation which reduces the real value of nominal government debt.

${ }^{13}$ Note the implicit assumption that a disaster simply reduces the face value of the bond (and does not affect its maturity).
} 
Using equation (6), we can find an equivalent expression for the equity return, often known as the investment return, which holds as long as investment is positive:

$$
\begin{aligned}
R_{t, t+1} & =\frac{F_{t+1}+D_{t+1}}{F_{t}}=\frac{\frac{\left(1-p b_{k}\right) K_{t+2}}{\phi^{\prime}\left(\frac{I_{t+1}}{K_{t+1}}\right)}+D_{t+1}}{\frac{\left(1-p b_{k}\right) K_{t+1}}{\phi^{\prime}\left(\frac{I_{t}}{K_{t}}\right)}} \\
& =\phi^{\prime}\left(\frac{I_{t}}{K_{t}}\right)\left[\frac{1-\delta+\phi\left(\frac{I_{t+1}}{K_{t+1}}\right)}{\phi^{\prime}\left(\frac{I_{t+1}}{K_{t+1}}\right)}\left(1-x_{t+1} b_{k}\right)+\frac{\alpha K_{t+1}^{\alpha} z_{t+1}^{1-\alpha} N_{t+1}^{1-\alpha}-I_{t+1}}{K_{t+1}}\right] .
\end{aligned}
$$

This expression is similar to that in Jermann (1998) or Kaltenbrunner and Lochstoer (2008), but for the presence of the term $\left(1-x_{t+1} b_{k}\right)$, which reflects the capital destruction following a disaster. Finally, I will also compute the price of two additional assets, a claim to the consumption process $C_{t}$, and a leveraged claim on consumption, defined by its payoff $C_{t}^{\lambda}$, where $\lambda$ is a leverage parameter. The motivation is that the dividend process implied by the model may not match well the dividend process in the data. In the real world, firms have financial leverage (they are not only equity-financed) and have operating leverage (e.g. fixed costs and labor contracts). This is a substantial source of profit volatility, which is not present in the model. Under some conditions, the only effect of this leverage is to modify the payout process. In the quantitative section I will use the model-implied price of a leveraged claim to consumption as the counterpart to the real-world equity. ${ }^{14}$

\subsection{Analytical results}

In this section, and before turning to the numerical analysis, we establish two simple, yet important, analytical results which follow directly from equation (4).

Proposition 1 Assume that the probability of disaster $p$ is constant, and that $b_{k}=b_{t f p}$ i.e. productivity and capital fall by the same amount if there is a disaster. Then, in a sample without disasters, the quantities implied by the model (consumption, investment, hours, output and capital) are the same as those implied by a model with no disasters $(p=0)$, but a different time discount factor $\beta^{*}=$ $\beta\left(1-p+p\left(1-b_{k}\right)^{v(1-\theta)}\right)^{\frac{1-\gamma}{1-\theta}}$. Moreover, assuming $\theta \geq 1, \beta^{*} \leq \beta$ if and only if $\gamma<1$. Asset prices, however, will be different under the two models; in particular, let $\bar{R}$ be the gross return on equity in normal times, and let $\bar{d}$ be the dividend-capital ratio, then in a disaster, the return is $\bar{R}\left(1-b_{k}\right)+b_{k} \bar{d}$, leading to a large equity premium.

Proof. Notice that if $b_{k}=b_{t f p}$, then $k^{\prime}=\frac{\left((1-\delta) k+\phi\left(\frac{i}{k}\right) k\right)}{e^{\mu+\sigma \varepsilon^{\prime}}}$ is independent of the realization of disaster $x^{\prime}$. Hence, we can rewrite the Bellman equation as

$$
g(k)=\max _{c, i, N}\left\{\begin{array}{c}
c^{v(1-\gamma)}(1-N)^{(1-v)(1-\gamma)} \\
+\beta e^{\mu v(1-\gamma)}\left(E_{x^{\prime}}\left(1-x^{\prime}+x^{\prime}\left(1-b_{t f p}\right)^{v(1-\theta)}\right) E_{\varepsilon^{\prime}} e^{\sigma \varepsilon^{\prime} v(1-\theta)} g\left(k^{\prime}\right)^{\frac{1-\theta}{1-\gamma}}\right)^{\frac{1-\gamma}{1-\theta}}
\end{array}\right\}
$$

i.e.:

$$
g(k)=\max _{c, i, N}\left\{c^{v(1-\gamma)}(1-N)^{(1-v)(1-\gamma)}+\beta^{*} e^{\mu v(1-\gamma)}\left(E_{\varepsilon^{\prime}} e^{\sigma \varepsilon^{\prime} v(1-\theta)} g\left(k^{\prime}\right)^{\frac{1-\theta}{1-\gamma}}\right)^{\frac{1-\gamma}{1-\theta}}\right\} .
$$

\footnotetext{
${ }^{14}$ The results are very similar if one defines dividends as a levered claim on output.
} 
We see that this is the same Bellman equation as the one in a standard neoclassical model, with discount rate $\beta^{*}$. As a result, the policy functions $c=C / z, i=I / z$, etc. are the same, so the implied quantities are the same, as long as no disaster occurs. ${ }^{15}$ Asset prices, on the other hand, are driven by the stochastic discount factor, which has the following expression (see the computational appendix):

$$
\begin{aligned}
M\left(k, k^{\prime}, \varepsilon^{\prime}, x^{\prime}\right)= & \beta\left(\frac{z^{\prime}}{z}\right)^{(\gamma-\theta) v+v(1-\gamma)-1}\left(\frac{c\left(k^{\prime}\right)}{c(k)}\right)^{v(1-\gamma)-1}\left(\frac{1-N\left(k^{\prime}\right)}{1-N(k)}\right)^{(1-v)(1-\gamma)} \times \ldots \\
& \left(\frac{g\left(k^{\prime}\right)^{\frac{1}{1-\gamma}}}{E_{z^{\prime}, x^{\prime}}\left(\left(\frac{z^{\prime}}{z}\right)^{v(1-\theta)} g\left(k^{\prime}\right)^{\frac{1-\theta}{1-\gamma}}\right)^{\frac{1}{1-\theta}}}\right)^{\gamma-\theta},
\end{aligned}
$$

and of course the term $z^{\prime} / z$ depends on the realization of a disaster $x^{\prime}$. In particular, in a disaster, the return on capital is

$$
R_{t, t+1}=\phi^{\prime}\left(\frac{I_{t}}{K_{t}}\right)\left[\frac{1-\delta+\phi\left(\frac{I_{t+1}}{K_{t+1}}\right)}{\phi^{\prime}\left(\frac{I_{t+1}}{K_{t+1}}\right)}\left(1-x_{t+1} b_{k}\right)+\frac{\alpha K_{t+1}^{\alpha} z_{t+1}^{1-\alpha} N_{t+1}^{1-\alpha}-I_{t+1}}{K_{t+1}}\right]
$$

and since the investment and the capital stock fall by the same amount, the investment rate is unaffected by the disaster; as a result the return is the same as if no disaster occurs, except for the term $\left(1-x_{t+1} b_{k}\right)=1-b_{k}$ since $x_{t+1}=1$; the dividend rate (profit less investment over capital) is itself unchanged.

Discussion of Result 1: This result is in the spirit of Tallarini (2000): fixing the asset pricing properties of a RBC model may not lead to any change in the quantity dynamics. An economy with a high equity risk premium due to disasters $(p>0)$ is observationally equivalent to the standard stochastic growth model $(p=0)$, with a different $\beta$. The standard calibration of the model without disasters (e.g., Cooley and Prescott (1995)) is to pick $\beta$ to match the observed return on capital. This calibration would pick $\beta^{*}$ and hence yield exactly the same implications as the model with disasters. Without the adjustment of $\beta$, the quantity implications are very slightly different. This is illustrated in the top panel of Figure 2 which depicts the impulse response of quantities to a TFP shock in three models: (a) the model with $p=0$, (b) the model with constant positive $p$, and (c) the benchmark calibration with time-varying $p$. The differences can be seen in the scale (y-axis), but they are tiny. For this calibration, we have $\beta=.99$, and $\beta^{*} \approx .9893$. Of course, asset prices will be different, and in particular the equity premium will be higher, as seen in the bottom panel of Figure 1 - the average returns are very different across the three models. The observational equivalence is broken in a long enough sample since disasters must occur. (The observational equivalence would also be broken if one observes assets contingent on disasters, since the prices would be different under the two models.)

The assumption $b_{k}=b_{t f p}$, simplifies the analysis substantially: the steady-state of the economy shifts due to a change in $z$, but the ratio of capital to productivity is unaffected by the disaster, i.e. the economy is in the same position relative to its steady-state after the disaster and before the disaster. As

\footnotetext{
${ }^{15}$ Even after a disaster, the policy functions are the same, i.e. given the new levels of $k$ and $p$ (or $K, z$, and $p$ ), the two models predict the same quantities. However, the destruction of capital in a disaster is not possible in the model with $p=0$ - the capital accumulation equation must hold without shocks (the large TFP decline is highly unlikely if shocks are normally distributed, but it is possible). If the capital stock is not observed, the observational equivalence result extends to any sample, including disasters or not.
} 
a result, a disaster will simply reduce investment, output, and consumption by a factor $b_{k}=b_{t f p}$, and hours will be unaffected. The economic intuition is that disasters lead both to a low marginal efficiency of capital and a low return on capital, hence the marginal value of capital does not depend on the state of the economy (disaster or not). As emphasized by Cochrane (2005), in a RBC model there is nothing that agents can do to increase or decrease the amount of uncertainty that they face. ${ }^{16}$

This same result implies that the "steady-state" level of capital stock will be changed, too. ${ }^{17}$ If risk aversion $\theta$ is greater than unity, and the IES is above unity, then $\beta^{*}<\beta$, so people save less and the steady-state capital stock is lower than in a model without disasters. While higher risk to productivity leads to higher precautionary savings, it is well known since Sandmo (1970) that rate-of-return risk can reduce savings (see Angeletos (2007), and Weil (1989) for related analysis).

While this first result is interesting, it is not fully satisfactory however, since the constant probability of disaster implies (nearly) constant risk premia, and hence P-D ratios are too smooth, and returns not volatile enough. ${ }^{18}$ This motivates extending the result for a time-varying $p$.

Proposition 2 Assume still that $b_{k}=b_{t f p}$, but let now p vary over time. Then, in a sample without disaster, the quantities implied by the model are the same as those implied by a model with no disasters, but with stochastic discounting (i.e. $\beta$ follows an exogenous stochastic process).

Proof. This follows from a similar argument: rewrite the Bellman equation as:

$$
g(k, p)=\max _{c, i, N}\left\{\begin{array}{c}
c^{v(1-\gamma)}(1-N)^{(1-v)(1-\gamma)} \\
+\beta e^{\mu v(1-\gamma)}\left(E_{x^{\prime}}\left(1-x^{\prime}+x^{\prime}\left(1-b_{t f p}\right)^{v(1-\theta)}\right) E_{\varepsilon^{\prime}, p^{\prime}} e^{\sigma \varepsilon^{\prime} v(1-\theta)} g\left(k^{\prime}, p^{\prime}\right)^{\frac{1-\theta}{1-\gamma}}\right)^{\frac{1-\gamma}{1-\theta}}
\end{array}\right\}
$$

then define $\beta(p)=\beta E_{x^{\prime}}\left(1-x^{\prime}+x^{\prime}\left(1-b_{t f p}\right)^{v(1-\theta)}\right)^{\frac{1-\gamma}{1-\theta}}$. By definition, $\beta\left(1-p+p\left(1-b_{t f p}\right)^{v(1-\theta)}\right)^{\frac{1-\gamma}{1-\theta}}$ and, if $\theta \geq 1, \beta$ is increasing in $p$ if and only if $\gamma<1$. We have:

$$
g(k, p)=\max _{c, i, N}\left\{(1-\beta) c^{v(1-\gamma)}(1-N)^{(1-v)(1-\gamma)}+\beta(p) e^{\mu v(1-\gamma)}\left(E_{\varepsilon^{\prime}, p^{\prime}} e^{\sigma \varepsilon^{\prime} v(1-\theta)} g\left(k^{\prime}, p^{\prime}\right)^{\frac{1-\theta}{1-\gamma}}\right)^{\frac{1-\gamma}{1-\theta}}\right\}
$$

i.e. the Bellman equation of a model with time-varying $\beta$, but no disasters.

Discussion of result 2: Result 2 shows that the time-varying risk of disaster has the same implications for quantities as a preference shock. It is well known that these shocks have significant effect on macroeconomic quantities (a point that we will quantify later). Hence, this version of the model breaks the "separation theorem" of Tallarini (2000): the source of time-varying risk premia in the model will affect quantity dynamics.

\footnotetext{
${ }^{16}$ An interesting extension of the model is to have technologies with different levels of riskiness, i.e. different exposures to disasters. Then, an increase in the aggregate risk of disaster may lead agents towards safer, lower-mean technologies.

${ }^{17}$ By steady-state we mean the level to which the capital stock converges in the absence of small shocks $\varepsilon$, if no disasters are realized. Intuitively, the same result should hold for the average (ergodic) capital stock, with the shocks $\varepsilon$ being realized.

${ }^{18}$ In an endowment economy where consumption and dividends follow random walk processes, these statements are exact. In our case, the processes are not exactly random walk, because of the TFP shock. However, the general intuition carries over, as we will see in the quantitative section.
} 
This result is interesting in light of the empirical literature which suggests that "preference shocks" or "equity premium shocks" may be important (Smets and Wouters (2003) and the many papers that follow). Chari, Kehoe and McGrattan (2009) complain that these shocks lack microfoundations. My model provides a simple microfoundation, which allows to tie these shocks to asset prices precisely. Of course, my model is much "smaller" than the medium-scale models of Smets and Wouters (2003), or Christiano, Eichenbaum and Evans (2005), but I conjecture that this equivalence should hold in larger versions.

Interestingly, this suggests that it is technically feasible to make DSGE models consistent with risk premia. A full non-linear solution of a medium-scale DSGE model is daunting. But under this result, we can solve the quantities of the model model for $p=0$ - which we know is well approximated with a log-linear approximation - and a shock process for $\beta$. Next, we can pick the process for $\beta$ to replicate the level and variation of risk premia.

Note that Propositions 1 and 2 require that $b_{k}=b_{t f p}$; analytical results are impossible without this assumption. But it is not innocuous. If disasters affect only TFP, then an increase in $p$ will lead people to want to hold more capital, for precautionary savings. This is true regardless of the IES. We discuss further and relax this assumption in Section 5.

\section{Quantitative Results}

In general, the model cannot be solved analytically, so I resort to a numerical approximation. Of course, a nonlinear method is crucial to analyze time-varying risk premia. I use a standard value function / policy function iteration algorithm, which is described in detail in an appendix.

This section first presents the calibration. Next, I study the implications of the model for business cycle quantities and for the first and second moments of asset returns, as well as for the predictability of stock returns. Finally, I discuss the cyclicality of asset returns.

\subsection{Calibration}

Parameters are listed in Table 1. The period is one quarter. Many parameters follow the business cycle literature (Cooley and Prescott (1995)). Risk aversion is 9, but note that this is the risk aversion over the consumption-hours bundle. Since the share of consumption in the utility index is .3, the effective risk aversion to a consumption gamble is 3 . For the baseline calibration, hours worked do not change when there is a disaster, hence this utility index is about three times less volatile than consumption. The intertemporal elasticity of substitution of consumption (IES) is set equal to 2, and adjustment costs are zero in the baseline model. One crucial element is the probability and size of disaster. I assume that $b_{k}=b_{t f p}=.43$ and the probability is .017 per year on average. This number is motivated by the evidence in Barro (2006) who reports this unconditional probability, and the risk-adjusted size of disaster is on average $43 \%$. In my model, with $b_{k}=b_{t f p}=.43$, both consumption and output fall by $43 \%$ if there is a disaster. (Barro actually uses the historical distribution of sizes of disaster. In his model, this distribution is equivalent to a single disaster with size $43 \%$.) The second crucial element is 
the persistence and volatility of movements in this probability of disaster. I assume that the log of the probability follows an $\operatorname{AR}(1)$ process:

$$
\log p_{t+1}=\rho_{p} \log p_{t}+\left(1-\rho_{p}\right) \log \bar{p}+\sigma_{p} \varepsilon_{p, t+1}
$$

where $\varepsilon_{p, t+1}$ is i.i.d. $N(0,1)$. The parameter $\bar{p}$ is picked so that the average probability is .017 per year, and I set $\rho_{p}=.99$ and the unconditional variance $\frac{\sigma_{p}^{2}}{1-\rho_{p}^{2}}=1$, which allows the model to fit reasonably well the volatility and predictability of risk premia. ${ }^{19}$ Regarding the default of government bonds during disasters, I follow the computations in Barro (2006): conditional on a disaster, government bonds default with probability .6, and the default rate is the size of the disaster. For simplicity, I assume that all bonds (no matter their maturity) default by the same amount if there is a disaster. ${ }^{20}$ Finally, the leverage parameters $\lambda$ is set to 3 , the standard value in the literature.

On top of this benchmark calibration, I will also present results from different calibrations (no disasters, constant probability of disasters, and in section 5 more extensions) to illustrate how the model works.

Some may argue that this calibration of disasters is extreme. A few remarks are in order. First, a long historical view makes this calibration sound more reasonable, as shown by Barro (2006) and Barro and Ursua (2008). An example is the U.K., which sounded very safe in 1900, but experienced a variety of very large negative shocks during the century. As shown by Martin (2008), the key ingredient is that there is a tiny probability of a very large shock.

The key assumption is that beliefs regarding the possibility of large drops in GDP vary over time. The recent financial crisis offers an illustration, with many investors and economists worrying about a new Great Depression. ${ }^{21}$ Some investors decided to pull out of the stock market in Fall 2008, partly out of the fear that the economy might continue to go down for a few more years, as in 1929. The recent crisis also illustrates some large declines in consumption or GDP: as an illustration, real consumption in Iceland is expected to drop by $7.1 \%$ in 2008 and $24.1 \%$ in 2009, according to the official government forecast (as of January 2009). According to the IMF World economic outlook (April 2009), output in Germany, Ireland, Ukraine, Japan, Latvia, Singapore, Taiwan, are expected to contract by respectively $5.6 \%, 8.0 \%, 8.0 \%, 6.2 \%, 12.0 \%, 10.0 \%, 7.5 \%$ in 2009 alone.

It is also possible to change the calibration - e.g., increase risk aversion, which is only 3 , and reduce the size of disasters. One can also employ fairly standard devices to boost the equity premium, and reduce the probability of disaster - e.g., the disasters may be concentrated on a limited set of agents, or some agents may have background risk (private businesses); or idiosyncratic risk might be countercyclical (becoming unemployed during the Great Depression was no fun). These features could all be added to the model, at a cost of complexity, and would likely reduce the magnitude of disasters required to make

\footnotetext{
${ }^{19}$ See Gabaix (2007), Gourio (2008b), and Wachter (2008) for a similar calibration of the endowment economy model. Also, this equation allows the probability to be greater than one, however I will approximate this process with a finite Markov chain, so this will not occur.

${ }^{20}$ Gabaix (2007) shows that if a disaster leads to a jump in inflation, then long-term bonds are more risky than short-term bonds, which can explain a variety of facts regarding the yield curve.

${ }^{21}$ Over the past year, some very prominent macroeconomists suggested that a new Great Depression is a distinct possibility, as illustrated by the quotes in the introduction.
} 
the model fit the data.

\subsection{Response to shocks}

\subsubsection{The dynamic effect of a disaster}

Figures 1 presents the dynamics of quantities following a disaster, for each of the three possible types of disasters: the benchmark model $\left(b_{k}=b_{t f p}=.43\right.$ as in the baseline calibration); a capital disaster $\left(b_{k}=.43\right.$ and $\left.b_{t f p}=0\right)$ whereby capital is destroyed but TFP is unaffected (e.g. a war); and a TFP disaster $\left(b_{t f p}=.43\right.$ and $\left.b_{k}=0\right)$. Of course, in post WWII U.S., no disasters have occurred, so these pictures are not to be matched to any data. Yet, they matter, because the properties of asset prices and quantities are driven by what would happen if there was a disaster. For instance, to generate a large equity premium, a model must endogenously generate that consumption and stock returns are extremely low during disasters. ${ }^{22}$ In the benchmark model, as implied by proposition 2 , there are no transitional dynamics following the disaster: consumption drops by a factor $1-b_{k}$, just like in the endowment economy of Rietz (1988) and Barro (2006); and the return on capital is approximately $1-b_{k}$ due to the capital destruction, hence the model is successful in generating an equity premium.

The case of a capital disaster is interesting because it leads endogenously to a recovery. The transitional dynamics here are exactly that of the standard Ramsey-Cass-Koopmans model (e.g., King and Rebelo (1993)). The return on capital is low on impact because of the destruction, but consumption does not fall as much as in the first case, given the anticipated recovery. Adding adjustment costs slows down the recovery, but makes the return on capital not as bad since marginal $\mathrm{Q}$ increases after the disaster.

Finally, a TFP disaster without a capital destruction leads to an excess of capital relative to its productivity. Investment falls to zero: the aggregate irreversibility constraint binds. Consumption and output then decline over time. ${ }^{23}$ In that case, the initial low return on capital is solely due to the binding irreversibility constraint - there is no capital destruction.

\subsubsection{The dynamic effect of a TFP shock}

As illustrated in figure 2, and discussed in the previous section, the dynamics of quantities in response to a TFP shock are similar to those of a standard model without disasters. Consumption, investment and employment are procyclical, and investment is the most volatile series. The model hence reproduces the basic success of the RBC model, and has the same deficiencies, e.g. employment is less volatile than in the data. The T-bill rate and the levered equity return are procyclical, but the return on physical capital is very smooth since there are no adjustment costs to capital adjustment. ${ }^{24}$ These dynamics are

\footnotetext{
${ }^{22}$ Since leisure enters the utility function, low hours worked could also potentially help. Moreover, Epstein-Zin utility implies that state prices are also determined by continuation utility, (expected future consumption and hours worked), i.e. the full path of transitional dynamics following a disaster.

${ }^{23}$ For this last case, the investment return is not correct, because the FOC for investment does not hold.

${ }^{24}$ This model generate some positive autocorrelation of consumption growth, due to capital accumulation, hence the dynamics of consumption are qualitatively similar to those in Bansal and Yaron (2004). This could in principle generate larger risk premia, however, as argued by Kaltenbrunner and Lochstoer (2008), this effect is not quantitatively very
} 
very similar for all the calibrations considered here, except when adjustment costs are large. ${ }^{25}$

\subsubsection{An increase in the probability of a disaster}

We can now perform the key experiment of an increase in the probability of disaster, which leads to an increase in risk premia. Figure 3 plots the impulse response function to such a shock. For this experiment, I assume that the probability of disaster is initially at its long-run average $(.017 \%$ per year) and doubles at time $t=6 .^{26}$ Investment decreases, and consumption increases, as in the analytical example of section 2, since the elasticity of substitution is assumed to be greater than unity. Employment decreases too, through an intertemporal substitution effect: the risk-adjusted return to savings is low and thus working today is less attractive. (This is in spite of a negative wealth effect which tends to push employment up.) Hence, output decreases because both employment and the capital stock decrease, even though there is no change in current or future total factor productivity. This is one of the main result of the paper: this shock to the "perceived risk" leads to a recession. After impact, total resources available shrink, and so does consumption. These results are robust to changes in parameter values, except of course for the IES which crucially determines the sign of the responses, and the assumption that $b_{k}=b_{t f p} \cdot{ }^{27}$ The size of adjustment costs, and the level of risk aversion, affect the magnitude of the response of investment and hours. These figures are consistent with proposition 2: the shock is equivalent, for quantities, to a preference shock to $\beta$.

The model predicts some negative comovement between consumption and investment, which may seem undesirable. However, this comovement depends on the labor supply specification, and the perfect correlation implied by the RBC model is at odds with the data.

Regarding asset prices, figure 4 reveals that following the shock, the risk premium on equity increases (the spread between the purple-square line and the blue-circle line increases), and the short rate decreases, as investors try to shift their portfolio towards safer assets. Hence, in the model, an increase in risk premia coincides with an economic expansion. On impact (at $t=6$ ), the increase in the risk premium lowers equity prices substantially. Here too, the return on physical capital is very smooth, since there are no adjustment costs. ${ }^{28}$

To conclude this section, figures 5 and 6 give a snapshot of a simulation for quantities and asset returns. These figures illustrate the key simplification of the model when $b_{k}=b_{t f p}$ - the time series (in $\log$ ) of quantities, except hours, all shift down by the factor $1-b_{k}$.

important if shocks are permanent and the IES is not small.

${ }^{25}$ In this case, employment can be countercyclical, as noted in Boldrin, Christiano and Fisher (2001).

${ }^{26}$ For clarity, there are no further shocks to the probability of disaster, no realized disaster, and no "normal shocks"

$\varepsilon$. The simulation is started of after the economy has been at rest for a long time (i.e. no realized disasters, no normal shocks, and no change in the probability of disaster).

${ }^{27}$ If the disaster only affects TFP, then an increase in the probability of disaster leads to more savings and hence a boom - the opposite sign of what is shown here; and this appears to be true regardless of the IES. This is consistent with the comparative statics for the average level of capital discussed in section 2.5.

${ }^{28} \mathrm{~A}$ different calibration with substantial adjustment costs can generate some return volatility. However, large adjustment costs have undesirable implications for business cycle dynamics. 


\subsection{First and second moments of asset returns and quantities}

Table 2 reports the standard business cycle moments obtained from model simulations for a sample without disasters. (Table 3 presents the same statistics in a full sample, i.e. a sample with disasters.) Row 2 shows the model when $b_{k}=b_{t f p}=0$, i.e. a standard RBC model with an elasticity of substitution of 2 - the success of the basic RBC model is clear: consumption is less volatile than output, and investment is more volatile than output. The volatility of hours is on the low side, a standard defect of the basic RBC model given this labor supply specification.

Introducing a constant probability of disaster, in row 3, does not change the moments significantly, consistent with the impulse responses shown in the previous section, and with proposition 1.. However, the presence of the new shock - change in the probability of disaster - leads to additional dynamics, which are visible in row 3. Specifically, the correlation of consumption with output is reduced. Consumption and employment become somewhat more volatile.

Turning to returns, table 4 and table 5 show that the benchmark model (row 3) can generate a large equity premium: 69 basis points per quarter for unlevered equity; and 195 basis points (close to $8 \%$ per year) for a levered equity. Note that these risk premium are obtained with a risk aversion over consumption equal to 3. Moreover, these risk premia are computed over short-term government bonds, which are not riskless in the model. Of course, without disasters, the model generates very small equity premia. Finally, whether these risk premia are calculated in a sample with disasters or without disasters does not matter much quantitatively - the risk premia are reduced by 10-30 basis point per quarter (see table 5).

The model generates a slightly negative term premium, consistent with the evidence for indexed bonds in the US and UK. ${ }^{29}$ This negative term premium is not due to what happens during disasters, since short-term bonds and long-term bonds are assumed to default by the same amount. As usual, TFPs shocks generate very small risk premia. The term premium is thus driven by the shocks to the probability of disaster. Long-term yields are more volatile than short-term yields, even though the probability of disaster is a stationary state variable; this seems to be due to the heteroskedasticity in the process for $p .{ }^{30} \mathrm{An}$ increase in the probability of disaster reduces interest rates, as the demand for savings rises, but it reduces the long yield more than the short yield, generating a positive return for long-term bonds, hence long-term bonds provide a hedge against these shocks (which are bad shocks since the present discounted value falls, even though consumption rises on impact). As a result, long-term bonds have a lower average return than the short-term bonds, and hence the yield curve is on average downward sloping. However, the model does not generate enough volatility in the term premium, compared to that observed in the (nominal) Treasuries market.

Table 6 shows that the model also does not generate enough volatility in unlevered equity returns (only 9 basis points in a sample without disasters). The intuition from the consumption-based model is that shocks to the probability of disaster affect the risk-free rate and the equity premium in roughly

\footnotetext{
${ }^{29} \mathrm{It}$ is not fully clear if one should interpret the bonds in the model as nominal or real. In normal times, there is no inflation; but during disasters there is some default, which may be interpreted as inflation.

${ }^{30}$ The process for $p$ is homoskedastic in $\log$, but heteroskedastic in level. The result that long term yields are more volatile than short term yields seems to depend somewhat on the calibration.
} 
similar ways, so that equity prices and average returns are not much affected by it. The intuition from the production-based point of view is that the return on capital is simply $1-\delta+M P K_{t+1}$, since there are no adjustment costs in the benchmark calibration. The volatility is significantly higher in a sample with disasters (2.12\% per quarter, see Table 7 ). These results are quite similar to Gourio (2008b) and Wachter (2008) in an endowment economy. Adding some financial or operating leverage, and possibly some wage rigidities may help here. Rather than incorporating in detail all these mechanisms, I consider the implications of the model for a claim to levered dividends or levered consumption. In this case, we find that the volatility is of the right order of magnitude: $5.16 \%$ per quarter. Overall, I conclude that the model does a good job at fitting the first two moments of asset returns, if one allows for leverage.

\subsection{Time series predictability of returns}

This section studies the ability of the model to match the evidence that returns are predictable. I concentrate on the basic regression of excess returns on price-dividend ratios. Table 8 presents the evidence by showing the slope coefficients, t-stat and $R^{2}$ of the basic regression:

$$
R_{t \rightarrow t+k}^{e}-R_{t \rightarrow t+k}^{f}=\alpha+\beta \frac{D_{t}}{P_{t}}+\varepsilon_{t+k} .
$$

As is well known, the slope coefficient $\beta$ is positive, significant, and it increases with horizon, as does the regression $R^{2}{ }^{31}$ The same table reports the results from running these regressions in simulated data from the model. As can be seen, the model also generates a positive slope, which increases with the horizon. Overall, and unsurprisingly in light of the results in Gabaix (2007), Gourio (2008b), and Wachter (2008) for endowment economies the model generates enough variation in risk premia over time to match the predictability evidence. ${ }^{32}$

\subsection{The relation between the stock market and output}

While most of the research has focused on the equity premium and the stock market volatility puzzle, the cyclicality of asset prices is also intriguing. Here I concentrate on the covariogram of HP-filtered output, denoted $y_{t}$, and the stock market, measured as the price-dividend ratio. Figure 7 shows the quantity

$$
\gamma_{k}=\operatorname{Cov}\left(y_{t+k}, \log \left(P_{t} / D_{t}\right)\right)
$$

for $k=-20,-19, \ldots, 0,1, \ldots, 20$ quarters. The black (full) line shows the data, reflecting the well-known pattern that output and the stock market are positively correlated. More precisely, the stock market leads GDP, so this covariance is highest for $k=5$ quarters.

The blue line (circles) displays the same quantity for the model with only TFP shock, i.e. the basic $\mathrm{RBC}$ model. The model generates a positive covariance between the price-dividend ratio and output,

\footnotetext{
${ }^{31}$ Of course, these regression results are somewhat fragile, as shown by Stambaugh (1999), Ang and Bekaert (2007), Boudoukh, Richardson and Whitelaw (2008), and Goyal and Welch (2008) among others. Yet, this regression has motivated the development of models with time-varying risk premia such as Campbell and Cochrane (1999) or Bansal and Yaron (2004). Finally and most importantly, these results show that the volatility of the price-dividend ratio is largely due to the volatility of expected returns rather than dividends.

32 [To add: predictability regression of dividend growth.]
} 
because TFP shocks increase future dividends (consumption here), hence leading to an increase in the $\mathrm{P}-\mathrm{D}$ ratio since the discount rate does not increase too much. The volatility of the P-D ratio is quite small however, but the correlation between changes in the P-D ratio and changes in output is high, since there is only one shock. Finally, note that the model cannot replicate the fact that the stock market leads GDP - the largest covariance is on impact.

The red line (crosses) shows the covariogram for the benchmark model, i.e. including both TFP shocks and shocks to the probability of disaster. The key result is that the covariance is now about twice higher for low vales of $k$. Hence, the model becomes much closer to the data. The P-D ratio is now substantially more volatile, but of course the covarances is not huge because the effect of a shock to $p$ on output is not huge. Finally, the model is still unable to replicate the fact that the stock market leads GDP, because the transitional dynamics are very small compared to the response on impact. ${ }^{33}$

\section{Robustness}

\subsection{TFP disasters vs. capital destruction}

An interesting issue is whether one should model disasters as reductions in TFP or destructions of the existing capital stock. Decreases in TFP arise for instance because of poor government policies, while destructions of the capital stock can be due to wars. Tables 9 through 11 present the impact of modeling disasters in these ways for the main results.

When disasters affect solely TFP, their effect is akin to that of standard TFP shocks, only larger. Hence, an increase in risk will lead to an increase in the capital stock for precautionary savings reasons. As a result, in this case, and regardless of the IES, an increase in the probability of disaster leads to a boom in investment and output. Beside this "counterintuitive" effect, the model generates a sizeable equity premium, but it underpredicts somewhat the volatility of returns.

When disasters solely affect the capital stock, the model does not generate a significant equity premium. There are two main reasons: first, consumption on impact does not fall by a very large amount, as consumers anticipate the recovery; second, with Epstein-Zin utility future values matter, and in this instance they indicate that the disaster is not as bad as thought, despite high working hours. Hence, capital disasters do not allow to match asset pricing facts.

\subsection{Disasters Dynamics}

As pointed out by Constantinides (2008), it is inadequate to model disasters as one-time jumps, since in reality they last more than a year. Barro et al. (2009) estimate a time-series process for disasters which takes into account the fact that disasters start, then may continue, and a recovery may follow. In the spirit of this exercise, I consider the following variation on the model: a disaster leads only to a $20 \%$ drop in both productivity and the capital stock. However, a disaster also makes the probability of a disaster next period increase to $50 \%$. Next period, either a disaster occurs, in which case the probability of a

\footnotetext{
${ }^{33}$ The model also has implications for the short rate and the term spread, which require further exploration given that we are pricing real bonds.
} 
further disaster remains at $50 \%$, or it doesn't, in which case this probability shifts back to a standard value. Tables 9 through 11 show the impact of this modification. While the disaster is substantially smaller (and the other parameters are kept constant), the model still generates a substantial equity premium - the fear of further disasters leads to an increase in the risk premium, and a further decline in asset prices, during the disaster. The model also gets reasonable return volatility. Figure 8 presents the response of macro quantities to a disaster (which is in this case not followed by a further disaster). Interestingly, this variation on the model makes investment drop by more than consumption, generating dynamics similar to the U.S. Great Depression. While this extension deserves more careful study, it is clear that adding some fear of further disasters is a very powerful ingredient.

\subsection{Recoveries in TFP following disasters}

As argued in Gourio (2008b) and estimated formally in Barro et al. (2009), there is evidence that output rebounds in the aftermath of a disaster. When the disaster is modeled as a pure destruction of capital $\left(b_{t f p}=0\right)$ this rebound is an outcome of the model - the usual neoclassical transitional dynamics bring back the economy to its steady-state i.e. it returns to its initial balanced growth path. However, when the disaster is modeled as a permanent reduction in total factor productivity $\left(b_{t f p}>0\right)$, there is no tendency for the economy to recover. To generate a recovery, one must assume that TFP itself will (perhaps randomly) recover. This section considers this extension.

To be added.

\subsection{Learning and business cycle dynamics}

Disasters are modeled for convenience as jumps, but in reality the contraction is not instantaneous. As a result, it is sometimes difficult for consumers and firms to determine if a decrease in productivity and output is a standard recession (a shock $\varepsilon$ in our setup) or is the start of a large depression.

A possible way to model this is to assume that disasters last two periods; they are observed only after they have ended. In real time, agents only observe productivity, which is driven by both shocks. As a result, a large decrease shock to productivity, due either to a disaster or to a large negative shock $\varepsilon$, will lead agents to anticipate a further decrease next period. Intuitively, the effect will be to make $\varepsilon$ and $p$ negatively correlated. This may help the model fit business cycle dynamics.

To be added.

\section{Conclusions and Future Work}

This work shows how introducing disasters into a standard RBC model improves its fit of asset return data, while preserving its relative success for quantity dynamics in response to TFP shocks, and finally creates some interesting new macroeconomic dynamics linked to the variation of risk premia. This setup has the advantage of being tractable, which allows to derive some analytical results and makes it easy 
to embed it into richer models. Researchers trying to connect business cycle dynamics with risk premia may find this a useful modeling tool.

There are several possible interesting extensions. First, it would be interesting to consider the effect of a time-varying risk of disaster in a richer business cycle model, e.g. one with collateral constraints or choice of financial leverage, or a standard New Keynesian model. Second, it would be interesting to consider richer dynamics for disasters - such as these sketched in section 5 - in more detail. Third, a change in the aggregate risk affects macroeconomic aggregates also by affecting the willingness to take on risk. This seems an interesting mechanism to explore: faced with an increase in the probability of an economic disaster, investors shift resources to technologies and projects which are less exposed to disasters. In doing so, they move the economy alongside a risk/return frontier, and pick projects which are less risky but also have lower expected returns. As a result, the expected output of the economy falls, and so does productivity. 


\section{References}

[1] Ang, Andrew and Geert Bekaert, 2007: "Stock Return Predictability: Is it There?", Review of Financial Studies, 20(3):651-707.

[2] Angeletos, Mario, 2007. "Uninsured Idiosyncratic Investment Risk and Aggregate Saving", Review of Economic Dynamics, 10(1):1-30.

[3] Angeletos, Mario, Philippe Aghion, Abhijit Banerjee and Kalina Manova, 2007. "Volatility and Growth: Credit Constraints and the Composition of Investment", mimeo MIT.

[4] Backus, David, Bryan Routledge and Stanley Zin, 2008. "The cyclical component in U.S. asset returns", mimeo NYU.

[5] Bansal, Ravi, and Amir Yaron, 2004. "Risks for the long run: A potential explanation of asset pricing puzzles." Journal of Finance 59, 1481-1509.

[6] Barro, Robert, 2006. "Rare disasters and asset markets in the twentieth century." Quarterly Journal of Economics 121, 823-866.

[7] Barro, Robert and Robert G. King, 1984. "Time-Separable Preferences and IntertemporalSubstitution Models of Business Cycles", Quarterly Journal of Economics, 99(4):817-839

[8] Barro, Robert, Emi Nakamura, Jon Steinsson, and Jose Ursua, 2009. "Crises and Recoveries in an Empirical Model of Consumption Disasters". Mimeo.

[9] Barro, Robert, and Jose Ursua, 2008. "Macroeconomic Crisis since 1870." Brookings Paper on Economic Activity.

[10] Beaudry, Paul and Franck Portier, 2006. "Stock Prices, News, and Economic Fluctuations," American Economic Review, 96(4):1293-1307.

[11] Bloom, Nicholas, 2008. "The effect of uncertainty shocks." Forthcoming, Econometrica.

[12] Boldrin, Michele, Lawrence J. Christiano, and Jonas Fisher, 2001. "Habit Persistence, Asset Returns, and the Business Cycle." American Economic Review, 91(1), pp. 149-166.

[13] Boudoukh, Jacob, Matthew Richardson and Robert Whitelaw, 2008: "The Myth of Long-Horizon Predictability", Review of Financial Studies, 21(4):1577-1605.

[14] Campanale, Claudio, Rui Castro, and Gian Luca Clementi. 2007. "Asset Pricing in a Production Economy with Chew-Dekel Preferences". Mimeo, NYU.

[15] Campbell, John Y. "Asset Prices, Consumption, and the Business Cycle." Handbook of Macroeconomics, 1999, Volume 1, Chapter 19, pp. 1231-1303.

[16] Campbell, John, and John Cochrane, 1999. By force of habit: A consumption-based explanation of aggregate stock market behavior. Journal of Political Economy 107, 205-251. 
[17] Campbell, John Y., and Robert Shiller. "The Dividend-Price Ratio and Expectations of Future Dividends and Discount Factors." Review of Financial Studies, 1988, 1, pp. 195-227.

[18] Campbell, John Y. and Motohiro Yogo, 2006. "Efficient Tests of Stock Return Predictability", Journal of Financial Economics, 81(1):27-60.

[19] Chari,V. V. , Patrick J. Kehoe and Ellen R. McGrattan, 2009. "New Keynesian models: not yet useful for policy analysis," forthcoming, AEJ: Macroeconomics.

[20] Christiano, Lawrence, Martin Eichenbaum, and Charles L. Evans, 2005. "Nominal Rigidities and the Dynamic Effects of a Shock to Monetary Policy", Journal of Political Economy, 113(1):1-45.

[21] Cochrane, John, 2004. "Asset Pricing." Princeton University Press.

[22] Cochrane, John, 2005. "Financial Markets and the Real Economy." Foundations and Trends in Finance, 1(1):1-101.

[23] Cochrane John, 2008: "The Dog that did not Bark", Review of Financial Studies, 21(4):1533-1575.

[24] Cooley, Thomas and Edward Prescott, 1995. "Frontiers of Business Cycle Research". Princeton University Press.

[25] Constantinides, 2008. "Comment"

[26] Croce, Max. "Long-Run Productivity Risk: A New Hope For Production-Based Asset Pricing." Mimeo, UNC.

[27] Devereux, Michael B., and Gregory W. Smith, "International Risk Sharing and Economic Growth," International Economic Review, XXXV (1994), 535-550.

[28] Dieckmann, Stephan, and Michael Gallmeyer, 2006. "The Equilibrium Allocation of Diffusive and Jump Risks with Heterogeneous Agents", Journal of Economic Dynamics and Control

[29] Epaulard, Anne, and Aude Pommeret, 2003. "Recursive utility, endogenous growth, and the welfare cost of volatility". Review of Economic Dynamics, 6(3):672-684.

[30] Epstein, Larry G. and Zin, Stanley E. "Substitution, Risk Aversion, and the Temporal Behavior of Consumption and Asset Returns: A Theoretical Framework." Econometrica, 1989, 57(4), pp. 937-969.

[31] Fama, Eugene, and Kenneth French, 1989. "Business conditions and expected returns on stocks and bonds." Journal of Financial Economics 25:23-49.

[32] Farhi, Emmanuel and Xavier Gabaix, 2008. "Rare disasters and exchange rates". Mimeo, Harvard.

[33] Fernandez-Villaverde, Jesus, Pablo Guerron-Quintana, Juan Rubio-Ramirez, and Martin Uribe, 2009. "Risk matters: the real effect of volatility shock", NBER working paper 14875. 
[34] Fernandez-Villaverde, Jesus, Ralph Koijen, Juan F. Rubio-Ramirez and Jules H. van Binsbergen, 2008. "Working with Epstein-Zin Preferences: Computation and Likelihood Estimation of DSGE Models with Recursive Preferences", Mimeo.

[35] Ferson, Wayne E., and Campbell R. Harvey, 1991. "The Variation of Economic Risk Premiums", Journal of Political Economy, 99(2):385-415.

[36] Gabaix, Xavier, 2007. "Variable rare disasters: An exactly solved framework for ten puzzles in macro-finance." Mimeo, NYU.

[37] Gabaix, Xavier, 2009. "Fixing the Asset Pricing Properties of RBC Models with Variable Rare Disasters." Mimeo, NYU.

[38] Gilchrist, Simon, and Egon Zakrajsek, 2007. "Investment and the Cost of Capital: New Evidence from the Corporate Bond Market". Mimeo, BU.

[39] Gourio, Francois. 2008. "Disasters and Recoveries." American Economic Review - Papers and Proceedings, 98(2): 68-73.

[40] Gourio, Francois, 2008b. "Time Series Predictability in the Disaster Model." Finance Research Letters, 5(4): 191-203.

[41] Gourio, Francois, 2008c. "Putty-clay technology and stock market volatility". Mimeo, BU.

[42] Goyal, Amit, and Io Welch, 2008: "A Comprehensive Look at the Empirical Performance of Equity Premium Prediction", Review of Financial Studies, 21(4):1455-1508.

[43] Jaccard, Ivan, 2008. "Asset Pricing, Habit Memory, and the Labor Market" Mimeo, ECB.

[44] Jaimovich, Nir and Sergio Rebelo, 2008. "Can News about the Future Drive the Business Cycle?" Forthcoming, American Economic Review.

[45] Jermann, Urban J., 1998. "Asset Pricing in Production Economies." Journal of Monetary Economics, 41(2), pp. 257-275.

[46] Julliard, Christian and Anita Gosh, 2008. "Can Rare Events Explain the Equity Premium Puzzle?", Mimeo LSE.

[47] Kaltenbrunner, Georg, and Lars Lochstoer, 2007. "Long-Run Risk through Consumption Smoothing." Mimeo, Columbia.

[48] Kehoe, Tim, and Edward Prescott, 2007. "Great Depressions of the Twentieth Century", Federal Reserve Bank of Minneapolis.

[49] Krebs 2003 "Human Capital Risk and Economic Growth", Quarterly Journal of Economics 118 (2003), 709-745.

[50] Kuehn, Lars, 2008. "Asset Pricing with Real Investment Commitment" Mimeo, CMU. 
[51] Jones, Larry, Rodolfo Manuelli, and Henry Siu, 2005a. "Fluctuations in convex models of endogenous growth, I: Growth effects", Review of Economic Dynamics, 8(4):780-804.

[52] Jones, Larry, Rodolfo Manuelli, and Henry Siu, 2005b. "Fluctuations in convex models of endogenous growth, II: Business cycle properties", Review of Economic Dynamics, 8(4):805:828.

[53] Jouini, Elyes, and Clotilde Napp, 2007. "Consensus Consumer and Intertemporal Asset Pricing with Heterogeneous Beliefs", Review of Economic Studies, 74:1149-1174.

[54] Judd, Kenneth, 1998. "Numerical methods in economics". MIT Press.

[55] Lettau, Martin, and Harald Uhlig, 2000, "Can Habit Formation Be Reconciled with Business Cycle Facts?", Review of Economic Dynamics, 3(1):79-99.

[56] Lettau, Martin and Sydney Ludvigson, 2002, "Time-varying risk premia and the cost of capital: An alternative implication of the Q theory of investment", Journal of Monetary Economics, 49(1):31-66.

[57] Lebhari and Srinivasan 1969

[58] Liu, Laura Xiaolei , Toni Whited and Lu Zhang, 2008. "Investment-based expected stock returns" Mimeo, U of Michigan.

[59] Longstaff, Francis, and Monika Piazzesi, 2004: "Corporate earnings and the equity premium", Journal of Financial Economics, 74(3):401-421.

[60] Lucas, Robert E., Jr, 2003. "Macroeconomic Priorities", American Economic Review, 93(1):1-14.

[61] Papanikolaou, Dimitris, 2008. "Investment-Specific Shocks and Asset Prices". Mimeo, Kellog.

[62] Philippon, Thomas, 2008. "The Bond Market's Q". Forthcoming, Quarterly Journal of Economics.

[63] Martin, Ian, 2007. "Consumption-Based Asset Pricing with Higher Cumulants". Mimeo, Stanford.

[64] Ramey, Garey and Valery Ramey, 1995. "Cross-Country Evidence on the Link Between Volatility and Growth Cross-Country Evidence on the Link Between Volatility and Growth", American Economic Review, 85(5):1138-1151.

[65] Rietz, Thomas, 1988. "The equity premium: A solution." Journal of Monetary Economics 22, $117-131$.

[66] Sandmo, 1970. “"”

[67] Santa Clara and Yan, 2008. "Crashes, Volatility, and the Equity Premium: Lessons from S\&P 500 Options". Review of Economics and Statistics, forthcoming.

[68] Schwert, G. William, 1989, "Why Does Stock Market Volatility Change Over Time?", Journal of Finance, 44(5):1115-1153.

[69] Schwert, G. William, 1990. "Stock Returns and Real Activity: A Century of Evidence Stock Returns and Real Activity: A Century of Evidence", Journal of Finance, 45(4):1237-1257. 
[70] Smets, Frank, and Ralf Wouters, 2003. "An Estimated Dynamic Stochastic General Equilibrium Model of the Euro Area". Journal of the European Economic Association, 1(5):1123-1175.

[71] Stambaugh, Robert, 1999: "Predictive Regressions", Journal of Financial Economics 54:375-421.

[72] Swanson, Eric and Glenn Rudebusch, 2008a. "The Bond Premium in a DSGE Model with Long-Run Real and Nominal Risks", Mimeo.

[73] Swanson, Eric and Glenn Rudebusch, 2008b. "Examining the Bond Premium Puzzle with a DSGE Model" Journal of Monetary Economics, forthcoming.

[74] Tallarini, Thomas D. Jr., 2000. "Risk-Sensitive Real Business Cycles." Journal of Monetary Economics, 45(3), pp. 507-532.

[75] Uhlig, Harald, 2006. "Macroeconomics and Asset Markets: Some Mutual Implications." University of Chicago Mimeo.

[76] Wachter, Jessica, 2008. "Can time-varying risk of rare disasters explain aggregate stock market volatility?" Mimeo, Wharton.

[77] Weil, Philippe, 1989. "Nonexpected Utility in Macroeconomics Nonexpected Utility in Macroeconomics", Quarterly Journal of Economics, 105(1):29-42.

[78] Weitzmann, Martin, 2007. "Subjective Expectations and Asset-Return Puzzles," American Economic Review, 97(4):1102-1130. 


\section{Appendix}

\subsection{Computational Method}

This method is presented for the case of a Cobb-Douglas production function, and a Cobb-Douglas utility function, but it can be used for arbitrary homogeneous of degree one production function and utility function. The Bellman equation for the "rescaled" problem is:

$$
g(k, p)=\max _{c, i, N}\left\{\begin{array}{c}
c^{v(1-\gamma)}(1-N)^{(1-v)(1-\gamma)} \\
+\beta e^{\mu v(1-\gamma)}\left(E_{p^{\prime}, \varepsilon^{\prime}, x^{\prime}} e^{\sigma \varepsilon^{\prime} v(1-\theta)}\left(1-x^{\prime}+x^{\prime}\left(1-b_{t f p}\right)^{v(1-\theta)}\right) g\left(k^{\prime}, p^{\prime}\right)^{\frac{1-\theta}{1-\gamma}}\right)^{\frac{1-\gamma}{1-\theta}}
\end{array}\right\},
$$

$$
\begin{aligned}
\text { s.t. } & : \\
c+i & =k^{\alpha} N^{1-\alpha}, \\
k^{\prime} & =\frac{\left(1-x^{\prime} b_{k}\right)\left((1-\delta) k+\phi\left(\frac{i}{k}\right) k\right)}{e^{\mu+\sigma^{\prime}}\left(1-x^{\prime} b_{t f p}\right)} .
\end{aligned}
$$

Because we take a power $\frac{1}{1-\gamma}$ of the value function, the max needs to be transformed in a min if $\gamma>1$. To approximate numerically the solution of this problem, I proceed as follows:

(1) Pick a grid for $k$, and a grid for $i$, and approximate the process for $p$ with a Markov chain with transition matrix $Q$. Discretize the normal shock $\varepsilon$, with probabilities $\pi(\varepsilon)$. I used 120 points for the grid for $k, 1200$ points for the grid for $i$, and 5 points for the grid for $\varepsilon$. Finally $Q$ is picked as in Rouwenhorst (1995). That method is a better approximation for highly persistent processes. I used 9 points for the grid for $p$.

(2) Compute for any $k, i$ in the grid the value $N(k, i)$ which solves

$$
R(k, i)=\max _{N}\left(k^{\alpha} N^{1-\alpha}-i\right)^{v}(1-N)^{(1-v)} .
$$

(3) The state space and action space are now discrete, so this is a standard discrete dynamic programing problem, which can be rewritten as follows, with one endogenous state, one exogenous state, and two additional shocks: a binomial variable $x$ equal to one if a disaster occurs (with probability $p$ ) and the normal shock $\varepsilon$ :

$g(k, p)=\max _{i}\left\{\begin{array}{c}R(k, i)+\beta e^{\mu v(1-\gamma)} \times \ldots \\ \left(\sum_{p^{\prime}, \varepsilon^{\prime}, x^{\prime} \in\{0,1\}} \pi\left(\varepsilon^{\prime}\right) Q\left(p, p^{\prime}\right) e^{\sigma \varepsilon^{\prime} v(1-\theta)} p r\left(x^{\prime}, p\right)\left(1-x^{\prime}+x^{\prime}\left(1-b_{t f p}\right)^{v(1-\theta)}\right) g\left(k^{\prime}, p^{\prime}\right)^{\frac{1-\theta}{1-\gamma}}\right)^{\frac{1-\gamma}{1-\theta}}\end{array}\right\}$,

$$
\begin{array}{ll}
\text { s.t. } & : \\
k^{\prime} & =\frac{\left(1-x^{\prime} b_{k}\right)\left((1-\delta) k+\phi\left(\frac{i}{k}\right) k\right)}{e^{\mu+\sigma \varepsilon^{\prime}}\left(1-x^{\prime} b_{t f p}\right)},
\end{array}
$$

where $\operatorname{pr}\left(x^{\prime}, p\right)=p 1_{x^{\prime}=1}+(1-p) 1_{x^{\prime}=0}=p x^{\prime}+(1-p)\left(1-x^{\prime}\right)$. I solve this Bellman equation using modified policy iteration ${ }^{34}$ (Judd (1998), p. 416), starting with a guess value close to zero. Recursive utility implies that the Blackwell sufficient conditions do not hold here, hence it is not obvious that the Bellman operator is a contraction. However, convergence occurs in practice as long as $\beta$ and the probability of disasters are not too large. Note that to compute the expectation, we need the value

\footnotetext{
${ }^{34}$ This turns out to be significantly faster than value iteration for this application.
} 
function outside the grid points. I use linear interpolation in the early steps of the iteration, then switch to spline interpolation. The motivation is that linear interpolation is more robust, hence it is easier to make the iterations converge; but spline interpolation is more precise.

(4) Given $g$, we have $V(K, z, p)=z^{v} g(k, p)^{\frac{1}{1-\gamma}}$. We also obtain the policy functions $C=z c(k, p)$, $I=z i(k, p), N=N(k, p)$, and the output policy function $Y=z k^{\alpha} N(k, p)^{1-\alpha}$.

(5) To compute asset prices, we need the stochastic discount factor, which is given by the standard formula:

$$
M_{t, t+1}=\beta\left(\frac{C_{t+1}}{C_{t}}\right)^{v(1-\gamma)-1}\left(\frac{1-N_{t+1}}{1-N_{t}}\right)^{(1-v)(1-\gamma)}\left(\frac{V_{t+1}}{E_{t}\left(V_{t+1}^{1-\theta}\right)^{\frac{1}{1-\theta}}}\right)^{\gamma-\theta} .
$$

Using homogeneity, the SDF between two states $s=(k, p)$ and $s^{\prime}=\left(k^{\prime}, p^{\prime}\right)$ is:

$$
\begin{aligned}
M\left(s, s^{\prime}, \varepsilon^{\prime}, x^{\prime}\right)= & \beta\left(\frac{z^{\prime} c\left(k^{\prime}, p^{\prime}\right)}{z c(k, p)}\right)^{v(1-\gamma)-1}\left(\frac{1-N\left(k^{\prime}, p^{\prime}\right)}{1-N(k, p)}\right)^{(1-v)(1-\gamma)}\left(\frac{z^{\prime v} g\left(k^{\prime}, p^{\prime}\right)^{\frac{1}{1-\gamma}}}{E_{z^{\prime}, p^{\prime}, x^{\prime}}\left(z^{\prime v(1-\theta)} g\left(k^{\prime}, p^{\prime}\right)^{\frac{1-\theta}{1-\gamma}}\right)^{\frac{1}{1-\theta}}}\right)^{\gamma-\theta} \\
= & \beta\left(\frac{z^{\prime}}{z}\right)^{(\gamma-\theta) v+v(1-\gamma)-1}\left(\frac{c\left(k^{\prime}, p^{\prime}\right)}{c(k, p)}\right)^{v(1-\gamma)-1} \times \ldots \\
& \ldots\left(\frac{1-N\left(k^{\prime}, p^{\prime}\right)}{1-N(k, p)}\right)^{(1-v)(1-\gamma)}\left(\frac{g\left(k^{\prime}, p^{\prime}\right)^{\frac{1}{1-\gamma}}}{E_{z^{\prime}, p^{\prime}, x^{\prime}}\left(\left(\frac{z^{\prime}}{z}\right)^{v(1-\theta)} g\left(k^{\prime}, p^{\prime}\right)^{\frac{1-\theta}{1-\gamma}}\right)^{\frac{1}{1-\theta}}}\right)^{\gamma-\theta} .
\end{aligned}
$$

Note that we first need to compute the conditional expectation which appears on the denominator of the last term. Denote $k^{\prime}=j\left(k, p, \varepsilon^{\prime}, x^{\prime}\right)$ the detrended capital next period, wich depends on the detrended investment $i(k, p)$ and on the realization of the shocks next period $\varepsilon^{\prime}$ and $x^{\prime}$ (but not $p^{\prime}$ ). The conditional expectation is obtained as:

$$
\begin{gathered}
E_{z^{\prime}, p^{\prime}, x^{\prime}}\left(\left(\frac{z^{\prime}}{z}\right)^{v(1-\theta)} g\left(k^{\prime}, p^{\prime}\right)^{\frac{1-\theta}{1-\gamma}}\right)^{\frac{1}{1-\theta}}= \\
=\sum_{p^{\prime}, \varepsilon^{\prime}} Q\left(p, p^{\prime}\right) \operatorname{Pr}\left(\varepsilon^{\prime}\right) e^{v(1-\theta) \mu+v(1-\theta) \sigma \varepsilon^{\prime}}\left(p\left(1-b_{t f p}\right)^{v(1-\theta)} g\left(j\left(k, p, \varepsilon^{\prime}, 1\right), p^{\prime}\right)^{\frac{1-\theta}{1-\gamma}}+(1-p) g\left(j\left(k, p, \varepsilon^{\prime}, 0\right), p^{\prime}\right)^{\frac{1-\theta}{1-\gamma}}\right) .
\end{gathered}
$$

(6) We can now obtain the price of a one-period asset, with payoff $d\left(k^{\prime}, z^{\prime}, p^{\prime}, x^{\prime}, \varepsilon^{\prime}\right)$. e.g. a pure risk-free asset $d=1$, or a short-term government bond: $d=1-q(1-r) x^{\prime}$, as

$$
P(k, p)=E_{x^{\prime}, p^{\prime}, \varepsilon^{\prime}} M\left(s, s^{\prime}, x^{\prime}, \varepsilon^{\prime}\right) d\left(k^{\prime}, z^{\prime}, p^{\prime}, x^{\prime}, \varepsilon^{\prime}\right) .
$$

For instance, for a pure risk-free asset, the formula is:

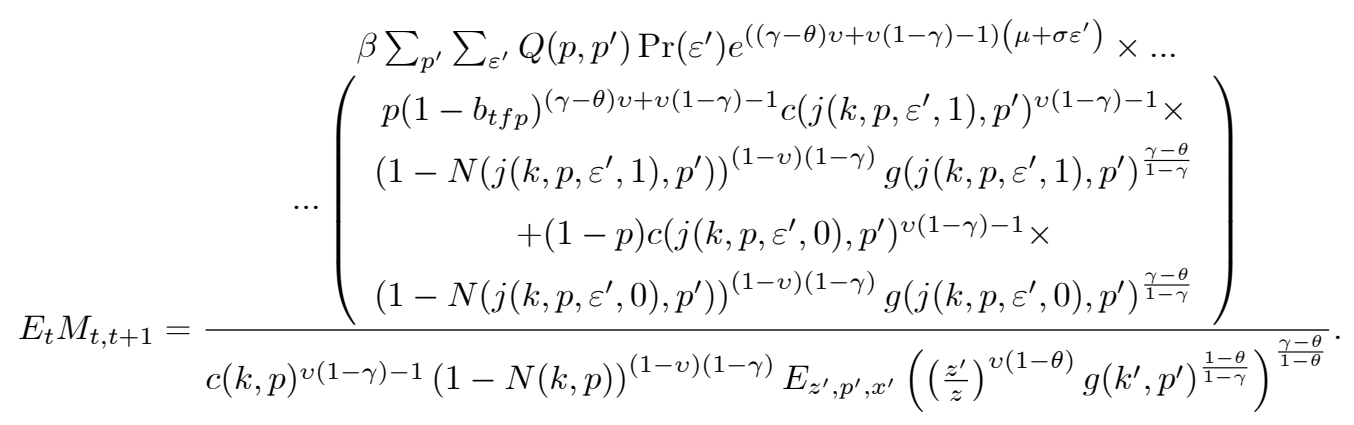

(7) Next, we can obtain the term structure of interest rates on government bonds, using the recursion:

$$
P_{n}(k, p)=E_{x^{\prime}, p^{\prime}, \varepsilon^{\prime}}\left(M\left(s, s^{\prime}, x^{\prime}, \varepsilon^{\prime}\right)\left(\left(1-x^{\prime} q(1-r)\right) P_{n-1}\left(k^{\prime}, p^{\prime}\right)\right)\right),
$$


where $q(1-r)$ is the expected loss rate of government bonds during disasters. It is assumed that government bonds are risk-free if there is no disaster.

(8), Finally, we can compute the price of equity claims. I consider three types of "equities". Define the representative firm's dividend as earnings less investment:

$$
D_{t}=Y_{t}-w_{t} N_{t}-I_{t}
$$

The first equity is simply a claim to the stream $\left\{D_{t}\right\}$. Let $F_{t}$ denote its price, which satisfies the standard recursion:

$$
F_{t}=E_{t}\left(M_{t, t+1}\left(F_{t+1}+D_{t+1}\right)\right) .
$$

Note that $D_{t}$ can be written as $D_{t}=z_{t} d\left(k_{t}, p_{t}\right)$, where $d(k, p)=\alpha k^{\alpha} N^{1-\alpha}-i(k, p)$. Hence, we can rewrite the firm value recursion as:

$$
z f(k, p)=E_{s^{\prime} \mid s}\left(M\left(s, s^{\prime}\right) \times\left(z^{\prime} d\left(k^{\prime}, p^{\prime}\right)+z^{\prime} f\left(k^{\prime}, p^{\prime}\right)\right)\right),
$$

where $F_{t}=z_{t} f\left(k_{t}, p_{t}\right)$. The equity return is then

$$
\begin{aligned}
R_{t+1}^{e} & =\frac{F_{t+1}+D_{t+1}}{F_{t}} \\
& =\frac{z_{t+1}}{z_{t}} \frac{f\left(k_{t+1}, p_{t+1}\right)+d\left(k_{t+1}, p_{t+1}\right)}{f\left(k_{t}, p_{t}\right)} .
\end{aligned}
$$

To solve the recursion 7 in practice, I iterate starting with an initial guess $f(k, p)=0$. The recursion can be rewritten as:

$$
\begin{aligned}
f(k, p)= & E_{s^{\prime} \mid s}\left(M\left(s, s^{\prime}\right) \frac{z^{\prime}}{z}\left(d\left(k^{\prime}, p^{\prime}\right)+f\left(k^{\prime}, p^{\prime}\right)\right)\right) \\
= & {\left[E_{p^{\prime}, \varepsilon^{\prime}, x^{\prime}}\left[\begin{array}{c}
\left.\left(\frac{z^{\prime}}{z}\right)^{(\gamma-\theta) v+v(1-\gamma)}\left(\frac{c\left(k^{\prime}, p^{\prime}\right)}{c(k, p)}\right)^{v(1-\gamma)-1}\left(\frac{1-N\left(k^{\prime}, p^{\prime}\right)}{1-N(k, p)}\right)^{(1-v)(1-\gamma)} \times \ldots\right] \\
\left(\frac{g\left(k^{\prime}, p^{\prime}\right)^{\frac{1}{1-\gamma}}}{E_{z^{\prime}, p^{\prime}, x^{\prime}}\left(\left(\frac{z^{\prime}}{z}\right)^{v(1-\theta)} g\left(k^{\prime}, p^{\prime}\right)^{\frac{1-\theta}{1-\gamma}}\right)^{\frac{1}{1-\theta}}}\right)^{\gamma-\theta}\left(d\left(k^{\prime}, p^{\prime}\right)+f\left(k^{\prime}, p^{\prime}\right)\right)
\end{array}\right] .\right.}
\end{aligned}
$$

This conditional expectation can be written down, as

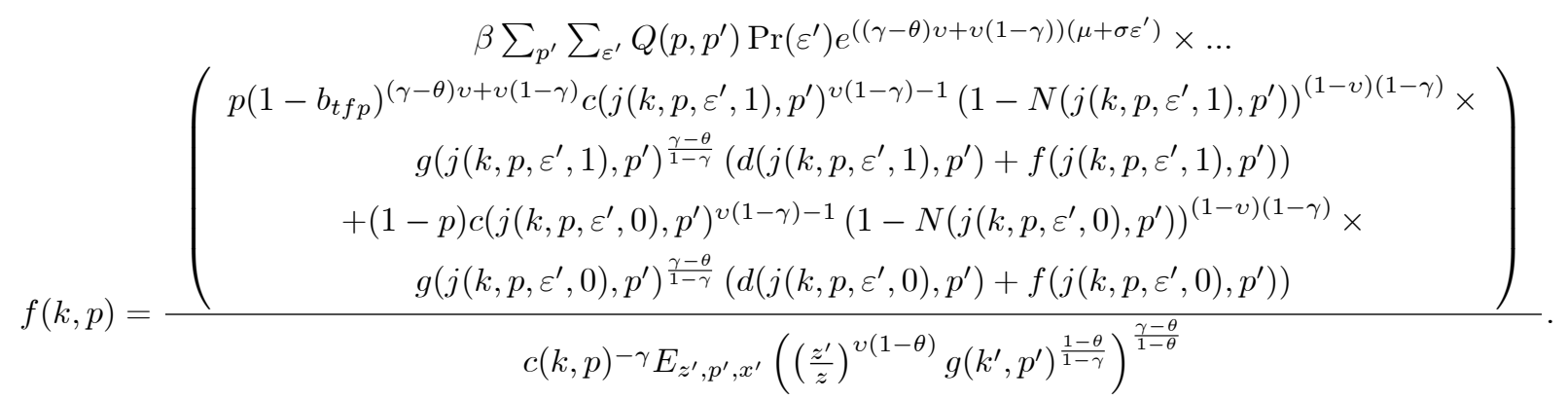

Note that a standard argument homogeneity argument (essentially, Hayashi's theorem; see Kaltenbrunner and Lochstoer (2008) for instance) implies that the ex-dividend firm value is:

$$
F_{t}=\frac{\left(1-p b_{k}\right) K_{t+1}}{\phi^{\prime}\left(\frac{I_{t}}{K_{t}}\right)},
$$


i.e. Tobin's $Q$ is $Q_{t}=\frac{F_{t}}{\left(1-p b_{k}\right) K_{t+1}}=\phi^{\prime}\left(\frac{I_{t}}{K_{t}}\right)$. Substituting this in the return equation (8) yields

$$
\begin{aligned}
R_{t, t+1} & =\frac{F_{t+1}+D_{t+1}}{F_{t}}=\frac{\frac{\left(1-p b_{k}\right) K_{t+2}}{\phi^{\prime}\left(\frac{I_{t+1}}{K_{t+1}}\right)}+D_{t+1}}{\frac{\left(1-p b_{k}\right) K_{t+1}}{\phi^{\prime}\left(\frac{I_{t}}{K_{t}}\right)}} \\
& =\phi^{\prime}\left(\frac{I_{t}}{K_{t}}\right)\left[\frac{1-\delta+\phi\left(\frac{I_{t+1}}{K_{t+1}}\right)}{\phi^{\prime}\left(\frac{I_{t+1}}{K_{t+1}}\right)}\left(1-x_{t+1} b_{k}\right)+\frac{\alpha K_{t+1}^{\alpha} N_{t+1}^{1-\alpha}-I_{t+1}}{K_{t+1}}\right] .
\end{aligned}
$$

This expression can be calculated using the quantities produced by the model in step (3). In practice it is useful to check that the results obtained using this method are the same as the results using the value $F_{t}$.

The second and third types of equity assume respectively that the payoff streams are $\left\{C_{t}^{\lambda}\right\}$ and

$\left\{D_{t}^{\lambda_{2}}\right\}$. It is easy to adapt the same method to price the claims to these assets. Finally, I obtain the model statistics by simulating 200 samples of length 500, started at the nonstochastic steady-state, and cutting off the first 300 periods. The Matlab(c) programs will be made available on my web page.

\subsection{Data Sources}

For the cross-correlogram: the stock market return is from CRSP (value-weighted including dividends). The short rate is from Ken French's website. The yield curve is from the Fama-Bliss data (1 to 5 years). The industrial production data is from FRED (series nickname INDPRO). I also used different monthly series to measure economic activity: employment (nickname PAYEMS), disposable income (DSPIC96), consumption (PCE96). All these series are monthly, and the data ranges from January 1959 to December 2007.

For the business cycle and return moments of Tables 2-7: consumption is nondurable + services consumption, investment is fixed investment, and output is GDP, from the NIPA Table 1.1.3, quarterly data 1947q1-2008q4. Hours is nonfarm business hours from the BLS productivity program (through FRED: HOABNS). The return data is from Ken French's webpage, (benchmark factors, aggregated to quarterly frequency, and deflated by the CPI (CPIAUCSL through FRED)).

Table 8: the data is taken from John Cochrane's webpage (Cochrane, 2008) and the regression results replicate exactly his specification (for the simple regression of return on dividend yield last year). This is also the CRSP value weighted return, and the risk-free rate is from Ibottson. 


\begin{tabular}{l|l|l}
\hline \hline Parameter & Greek Letter & Value \\
\hline Capital share & $\alpha$ & .34 \\
Depreciation rate & $\delta$ & .02 \\
Adjustment cost curvature & $\eta$ & 0 \\
Trend growth of TFP & $\mu$ & .005 \\
Discount factor & $\beta$ & .99 \\
IES & $1 / \gamma$ & 2 \\
Share of consumption in utility & $v$ & .3 \\
Risk aversion over the cons.-leis. bundle & $\theta$ & 9 \\
Standard deviation of ordinary TFP shock & $\sigma$ & .01 \\
Size of disaster in TFP & $b_{t f p}$ & .43 \\
Size of disaster for capital & $b_{k}$ & .43 \\
Persistence of log $(p)$ & $\rho_{p}$ & .99 \\
Unconditional std. dev. of log $(p)$ & $\sigma_{p}$ & 1 \\
Leverage & $\lambda$ & 3 \\
Recovery rate for bonds during disasters & $1-r(1-b)$ & .828 \\
\hline \hline
\end{tabular}

Table 1: Parameter values for the benchmark model. The time period is one quarter.

\begin{tabular}{l|l|l|l|l|l|l|}
\hline \hline Sample without disasters & $\frac{\sigma(\Delta \log C)}{\sigma(\Delta \log Y)}$ & $\frac{\sigma(\Delta \log I)}{\sigma(\Delta \log Y)}$ & $\frac{\sigma(\Delta \log N)}{\sigma(\Delta \log Y)}$ & $\sigma(\Delta \log Y)$ & $\rho_{C, Y}$ & $\rho_{I, Y}$ \\
\hline \hline Data & 0.57 & 2.68 & 0.92 & 0.98 & 0.45 & 0.68 \\
\hline \hline No disaster $\left(b_{k}=b_{t f p}=0\right)$ & 0.43 & 2.88 & 0.43 & 0.91 & 0.97 & 0.99 \\
Constant p $\left(b_{k}=b_{t f p}=.43\right)$ & 0.44 & 2.93 & 0.43 & 0.91 & 0.97 & 0.99 \\
Benchmark $\left(b_{k}=b_{t f p}=.43\right)$ & $\mathbf{0 . 4 9}$ & $\mathbf{3 . 2 1}$ & $\mathbf{0 . 4 9}$ & $\mathbf{0 . 9 3}$ & $\mathbf{0 . 8 4}$ & $\mathbf{0 . 9 7}$ \\
\hline \hline
\end{tabular}

Table 2: Business cycle quantities: second moments implied by the model, for different calibrations. Quarterly data. This is based on a sample without disasters. rho(C,Y) and rho(I,Y) are the correlation of the growth rate of $\mathrm{C}$ and of $\mathrm{Y}$, and I of $\mathrm{Y}$, respectively. Data sources in appendix. 


\begin{tabular}{l|l|l|l|l|l|l|}
\hline \hline Sample with disasters & $\frac{\sigma(\Delta \log C)}{\sigma(\Delta \log Y)}$ & $\frac{\sigma(\Delta \log I)}{\sigma(\Delta \log Y)}$ & $\frac{\sigma(\Delta \log N)}{\sigma(\Delta \log Y)}$ & $\sigma(\Delta \log Y)$ & $\rho_{C, Y}$ & $\rho_{I, Y}$ \\
\hline \hline Data & 0.57 & 2.68 & 0.92 & 0.98 & 0.45 & 0.68 \\
\hline \hline No disaster $\left(b_{k}=b_{t f p}=0\right)$ & 0.44 & 2.89 & 0.43 & 0.91 & 0.97 & 0.99 \\
Constant p $\left(b_{k}=b_{t f p}=.43\right)$ & 0.94 & 1.29 & 0.12 & 3.37 & 0.99 & 0.94 \\
Benchmark $\left(b_{k}=b_{t f p}=.43\right)$ & 0.94 & 1.39 & 0.14 & 3.23 & 0.95 & 0.92 \\
\hline \hline
\end{tabular}

Table 3: Business cycle quantities: second moments implied by the model, for different calibrations. Quarterly data. This is based on a full sample (i.e., including disasters).

\begin{tabular}{lllllll}
\hline \hline Sample without disasters & $E\left(R_{f}\right)$ & $E\left(R_{b}\right)$ & $E\left(R_{e}\right)$ & $E\left(R_{c}\right)$ & $E\left(R_{c, l e v}\right)$ & $E\left(R_{l t b}-R_{b}\right)$ \\
\hline \hline Data & - & 0.21 & 1.91 & - & 1.91 & - \\
\hline \hline No disaster $\left(b_{k}=b_{t f p}=0\right)$ & 1.22 & 1.22 & 1.22 & 1.23 & 1.29 & 0.00 \\
Constant p $\left(b_{k}=b_{t f p}=.43\right)$ & 0.07 & 0.56 & 1.29 & 1.30 & 1.83 & 0.00 \\
Benchmark $\left(b_{k}=b_{t f p}=.43\right)$ & $\mathbf{0 . 0 8}$ & $\mathbf{0 . 5 3}$ & $\mathbf{1 . 2 2}$ & $\mathbf{1 . 3 7}$ & $\mathbf{2 . 4 8}$ & $\mathbf{- 0 . 2 8}$ \\
\hline \hline
\end{tabular}

Table 4: Mean returns implied by the model for (a) pure risk-free asset, (b) a one-quarter govt bond, (c) a claim to dividends (d) a claim on consumption (e) a leveraged claim on consumption (f) the difference between the long-term (20 quarters) bond and the short-term bond. Quarterly data. Statistics computed in a sample without disasters. Data sources in appendix.

\begin{tabular}{l|l|l|l|l|l|l|}
\hline \hline Sample with disasters & $E\left(R_{f}\right)$ & $E\left(R_{b}\right)$ & $E\left(R_{e}\right)$ & $E\left(R_{c}\right)$ & $E\left(R_{c, l e v}\right)$ & $E\left(R_{l t b}-R_{b}\right)$ \\
\hline \hline Data & - & 0.21 & 1.91 & - & 1.91 & - \\
\hline \hline No disaster $\left(b_{k}=b_{t f p}=0\right)$ & 1.22 & 1.22 & 1.22 & 1.23 & 1.28 & -0.00 \\
Constant p $\left(b_{k}=b_{t f p}=.43\right)$ & 0.07 & 0.45 & 1.11 & 1.13 & 1.50 & 0.00 \\
Benchmark $\left(b_{k}=b_{t f p}=.43\right)$ & 0.08 & 0.42 & 1.04 & 1.20 & 2.16 & -0.29 \\
\hline \hline
\end{tabular}

Table 5: Mean returns implied by the model. Quarterly data. This is based on a full sample (i.e., including disasters).

\begin{tabular}{l|l|l|l|l|l|l|}
\hline \hline Sample without disasters & $\sigma\left(R_{f}\right)$ & $\sigma\left(R_{b}\right)$ & $\sigma\left(R_{e}\right)$ & $\sigma\left(R_{c}\right)$ & $\sigma\left(R_{c, l e v}\right)$ & $\sigma\left(R_{l t b}-R_{b}\right)$ \\
\hline \hline Data & - & 0.81 & 8.14 & - & 8.14 & - \\
\hline \hline No disaster $\left(b_{k}=b_{t f p}=0\right)$ & 0.08 & 0.08 & 0.08 & 0.52 & 2.44 & 0.00 \\
\hline Constant $\mathrm{p}\left(b_{k}=b_{t f p}=.43\right)$ & 0.08 & 0.08 & 0.08 & 0.52 & 2.37 & 0.00 \\
\hline Benchmark $\left(b_{k}=b_{t f p}=.43\right)$ & $\mathbf{0 . 6 8}$ & $\mathbf{0 . 4 2}$ & $\mathbf{0 . 0 9}$ & $\mathbf{0 . 9 5}$ & $\mathbf{5 . 1 6}$ & $\mathbf{0 . 1 4}$ \\
\hline \hline
\end{tabular}

Table 6: Standard deviations of returns implied by the model for (a) pure risk-free asset, (b) a onequarter govt bond, (c) a claim to dividends (d) a claim on consumption (e) a leveraged claim on consumption (f) the difference between the long-term (20 quarters) bond and the short-term bond. Quarterly data. Statistics computed in a sample without disasters. Data sources in appendix. 


\begin{tabular}{l|l|l|l|l|l|l|}
\hline \hline Sample with disasters & $\sigma\left(R_{f}\right)$ & $\sigma\left(R_{b}\right)$ & $\sigma\left(R_{e}\right)$ & $\sigma\left(R_{c}\right)$ & $\sigma\left(R_{c, l e v}\right)$ & $\sigma\left(R_{l t b}-R_{b}\right)$ \\
\hline \hline Data & - & 0.81 & 8.14 & - & 8.14 & - \\
\hline \hline No disaster $\left(b_{k}=b_{t f p}=0\right)$ & 0.08 & 0.08 & 0.08 & 0.52 & 2.44 & 0.00 \\
Constant $\mathrm{p}\left(b_{k}=b_{t f p}=.43\right)$ & 0.08 & 0.08 & 2.40 & 2.54 & 5.45 & 0.00 \\
Benchmark $\left(b_{k}=b_{t f p}=.43\right)$ & 0.83 & 0.51 & 2.27 & 2.60 & 7.14 & 0.17 \\
\hline \hline
\end{tabular}

Table 7: Standard deviation of returns implied by the model. Quarterly data. This is based on a full sample (i.e., including disasters).

\begin{tabular}{llll|lll}
\hline \hline \multicolumn{5}{c|}{ Data } & & \multicolumn{3}{l}{ Model } \\
\hline \hline horizon & coeff. & t-stat & R2 & coeff. & t-stat & R2 \\
\hline 1 & 3.83 & 2.47 & 0.07 & 1.03 & 1.00 & 0.04 \\
2 & 7.42 & 3.13 & 0.11 & 5.84 & 3.05 & 0.17 \\
3 & 11.57 & 4.04 & 0.18 & 10.76 & 4.34 & 0.28 \\
4 & 15.81 & 4.35 & 0.20 & 15.93 & 5.30 & 0.37 \\
\hline \hline
\end{tabular}

Table 8: Regression of stock market excess return on lagged dividend yield, for different horizons, in the model and in the data. The table reports the slope coefficient, the t-stat (based on the OLS standard error), and R2, for each horizon from 1 year to 4 years. In the model, these regressions are computed using the return on a levered claim on consumption, for the benchmark calibration. Data from Cochrane (2008).

\begin{tabular}{l|l|l|l|l|l|l|}
\hline \hline Robustness & $\frac{\sigma(\Delta \log C)}{\sigma(\Delta \log Y)}$ & $\frac{\sigma(\Delta \log I)}{\sigma(\Delta \log Y)}$ & $\frac{\sigma(\Delta \log N)}{\sigma(\Delta \log Y)}$ & $\sigma(\Delta \log Y)$ & $\rho_{C, Y}$ & $\rho_{I, Y}$ \\
\hline \hline Data & 0.57 & 2.68 & 0.92 & 0.98 & 0.45 & 0.68 \\
Benchmark $\left(b_{k}=b_{t f p}=.43\right)$ & $\mathbf{0 . 4 9}$ & $\mathbf{3 . 2 1}$ & $\mathbf{0 . 4 9}$ & $\mathbf{0 . 9 3}$ & $\mathbf{0 . 8 4}$ & $\mathbf{0 . 9 7}$ \\
\hline \hline Capital disasters $\left(b_{t f p}=0\right)$ & 0.52 & 3.95 & 0.60 & 0.96 & 0.62 & 0.92 \\
\hline TFP disasters $\left(b_{k}=0\right)$ & 0.61 & 7.40 & 0.80 & 1.12 & 0.34 & 0.90 \\
\hline Multiperiod disasters & 0.63 & 5.24 & 0.78 & 1.04 & 0.36 & 0.91 \\
\hline \hline
\end{tabular}

Table 9: Extensions of the model: Business cycle quantities. This is based on a sample without disasters.

\begin{tabular}{lllllll}
\hline \hline Robustness & $E\left(R_{f}\right)$ & $E\left(R_{b}\right)$ & $E\left(R_{e}\right)$ & $E\left(R_{c}\right)$ & $E\left(R_{c, l e v}\right)$ & $E\left(R_{l t b}-R_{b}\right)$ \\
\hline \hline Data & - & 0.21 & 1.91 & - & 1.91 & - \\
Benchmark $\left(b_{k}=b_{t f p}=.43\right)$ & $\mathbf{0 . 0 8}$ & $\mathbf{0 . 5 3}$ & $\mathbf{1 . 2 2}$ & $\mathbf{1 . 3 7}$ & $\mathbf{2 . 4 8}$ & $\mathbf{- 0 . 2 8}$ \\
\hline \hline Capital disasters $\left(b_{t f p}=0\right)$ & 1.09 & 1.19 & 1.33 & 1.23 & 1.30 & 0.00 \\
\hline \hline TFP disasters $\left(b_{k}=0\right)$ & 0.85 & 1.12 & 0.87 & 1.32 & 1.81 & -0.10 \\
\hline \hline Multiperiod disasters & 0.76 & 0.96 & 1.27 & 1.31 & 2.18 & -1.31 \\
\hline \hline
\end{tabular}

Table 10: Extensions of the model: Mean returns. Statistics computed in a sample without disasters. 


\begin{tabular}{l|l|l|l|l|l|l|}
\hline \hline Robustness & $\sigma\left(R_{f}\right)$ & $\sigma\left(R_{b}\right)$ & $\sigma\left(R_{e}\right)$ & $\sigma\left(R_{c}\right)$ & $\sigma\left(R_{c, l e v}\right)$ & $\sigma\left(R_{l t b}-R_{b}\right)$ \\
\hline \hline Data & - & 0.81 & 8.14 & - & 8.14 & - \\
Benchmark $\left(b_{k}=b_{t f p}=.43\right)$ & $\mathbf{0 . 6 8}$ & $\mathbf{0 . 4 2}$ & $\mathbf{0 . 0 9}$ & $\mathbf{0 . 9 5}$ & $\mathbf{5 . 1 6}$ & $\mathbf{0 . 1 4}$ \\
\hline \hline Capital disasters $\left(b_{t f p}=0\right)$ & 0.16 & 0.11 & 0.10 & 0.55 & 2.45 & 0.01 \\
\hline \hline TFP disasters $\left(b_{k}=0\right)$ & 0.31 & 0.20 & 1.67 & 0.74 & 3.54 & 0.10 \\
\hline \hline Multiperiod disasters & 1.00 & 0.65 & 0.09 & 0.58 & 5.03 & 0.60 \\
\hline \hline
\end{tabular}

Table 11: Extensions of the model: standard deviation of returns implied by the model. Quarterly data. Sample without disasters.
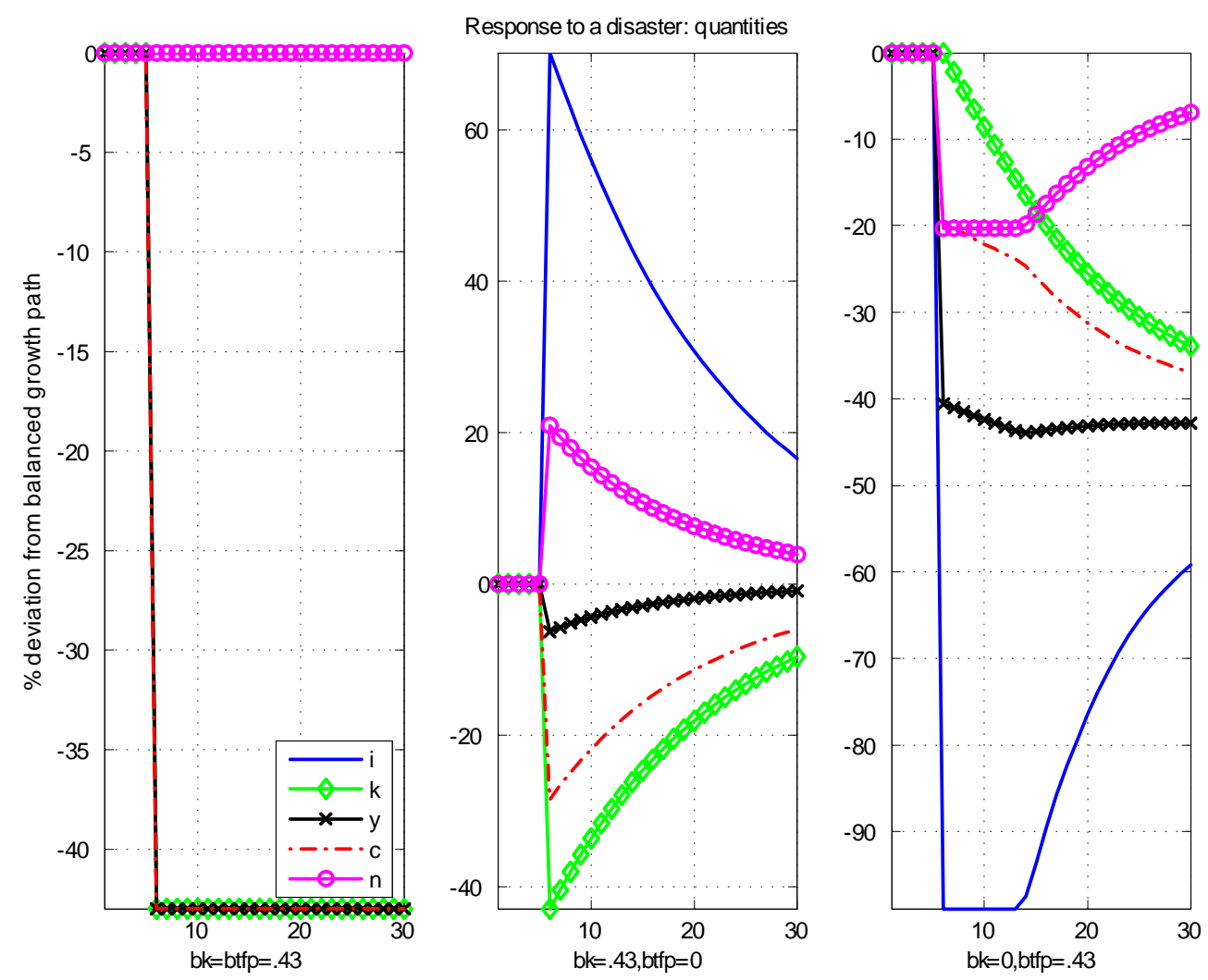

Figure 1: The different types of disasters. Response of quantities (Consumption C, Investment I, Capital K, Employmen N, Output Y) to a disaster at $t=6$, in $\%$ deviation from balanced growth path. Left panel: $b_{k}=b_{t f p}$; Middle panel: $b_{k}=.43, b_{t f p}=0$. Right panel: $b_{t f p}=.43, b_{k}=0$. 

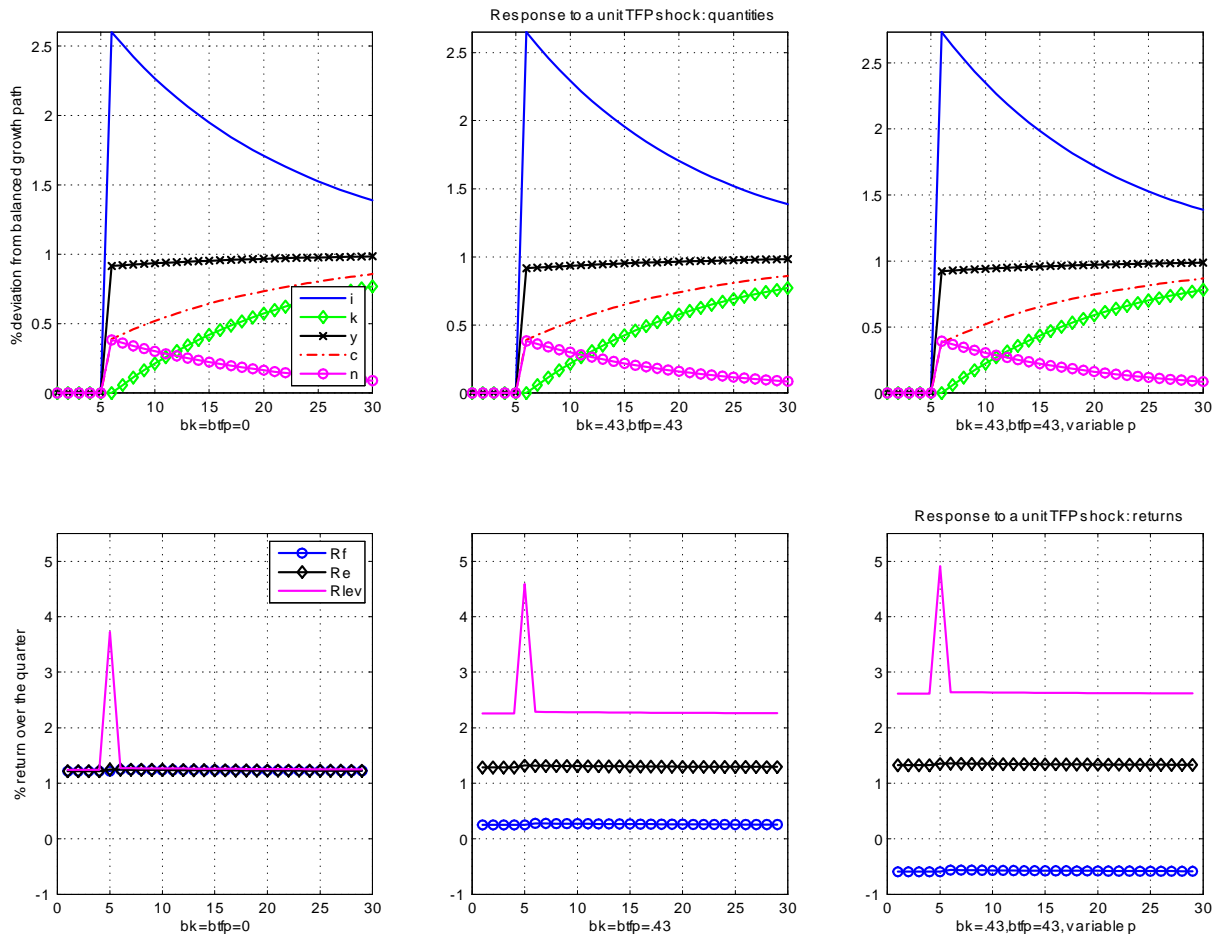

Figure 2: (Near) Observational equivalence of quantity dynamics to a TFP shock. The figure plots the impulse response function of quantities $(\mathrm{C}, \mathrm{I}, \mathrm{N}, \mathrm{K}, \mathrm{Y})$ and returns (risk-free rate, equity return, levered equity) to a permanent TFP shock at $t=6$. Left panel: model without disasters. Middle panel: model with constant probability of disasters. Right panel: model with time-varying probability of disaster (benchmark). All other parameters (including $\beta$ ) are kept constant across the three panels. 


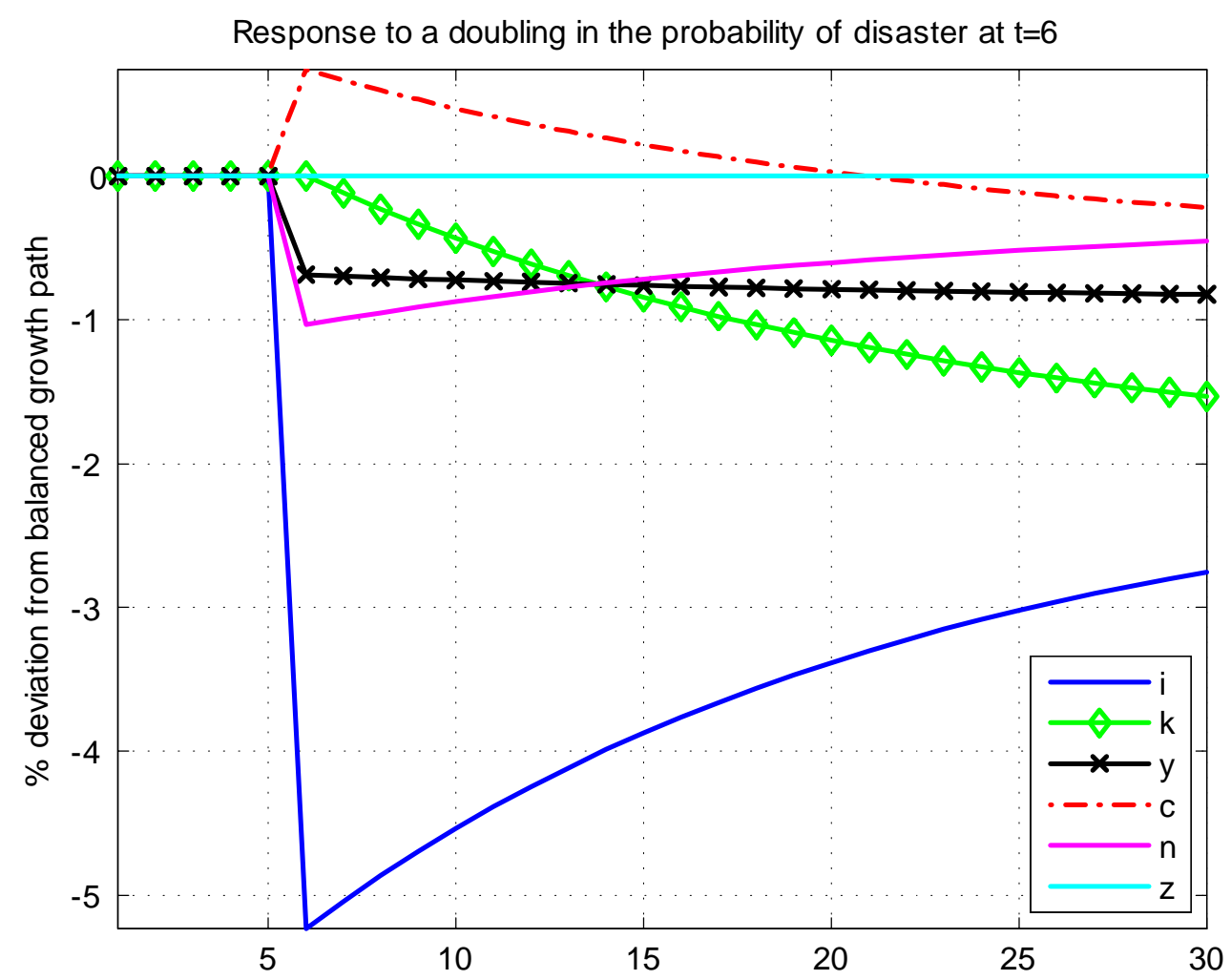

Figure 3: The effect of an increase in the probability of economic disaster. on macroeconomic quantities. Impulse response of $(\mathrm{C}, \mathrm{I}, \mathrm{K}, \mathrm{N}, \mathrm{Y})$ to a shock to the probability of disaster at $t=6$. The probability of disaster goes from its long-run average (.425\% per quarter) to twice its long-run average and stays there. For clarity, this figure assumes that there is no shock to TFP, and no disaster realized. 

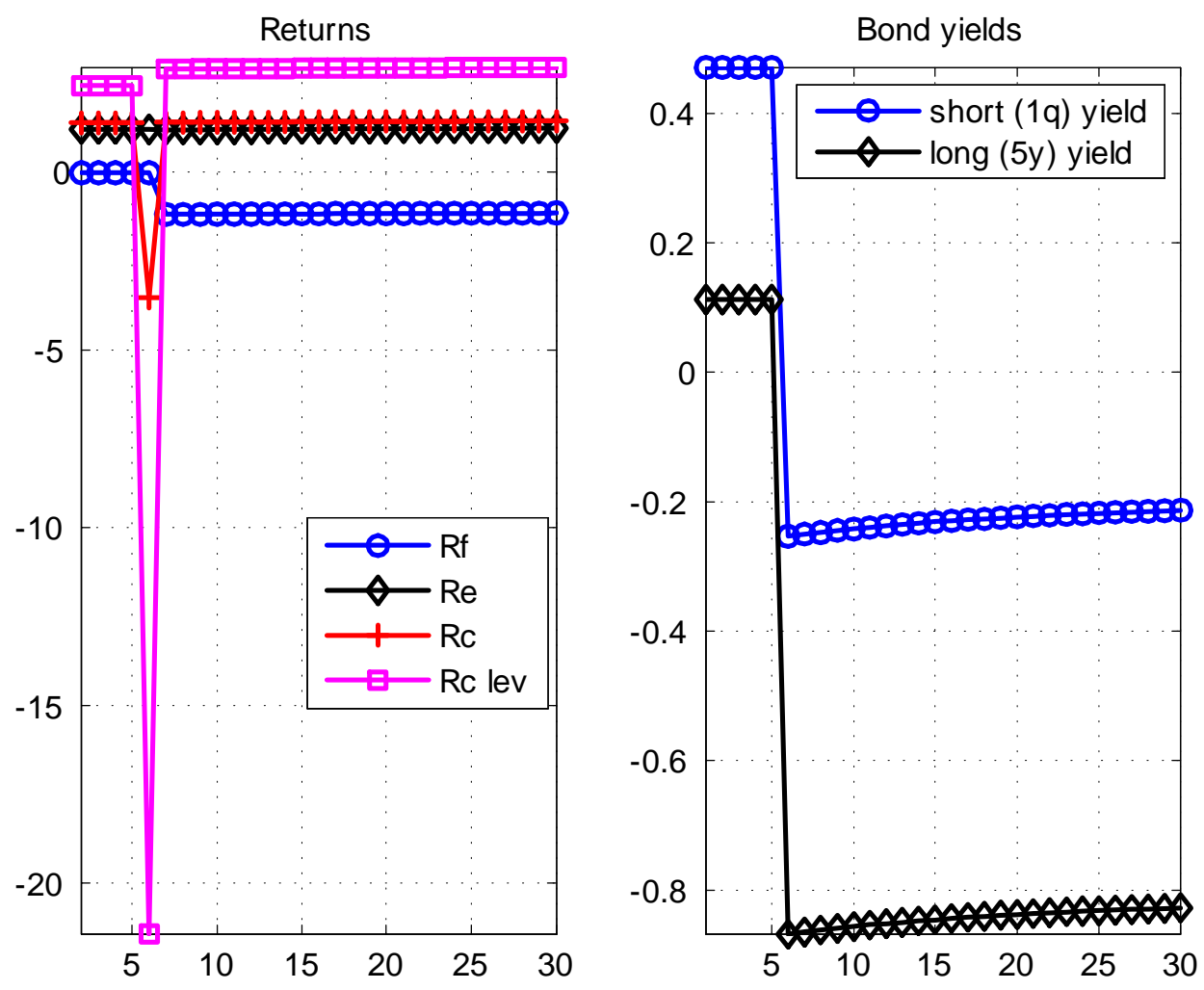

Figure 4: The effect of an increase in the probability of economic disaster on asset returns. Impulse response of asset returns to a shock to the probability of disaster at $t=6$. The probability of disaster doubles from its long-run average $(t=1$ to $t=5)$ to double its long-run average (from $t=6$ on). The left panel shows the return on the pure risk-free asset, the equity asset, and a levered claim to consumption. The right panel shows the short (1 quarter) and long (20 quarters) yields on government debt. 


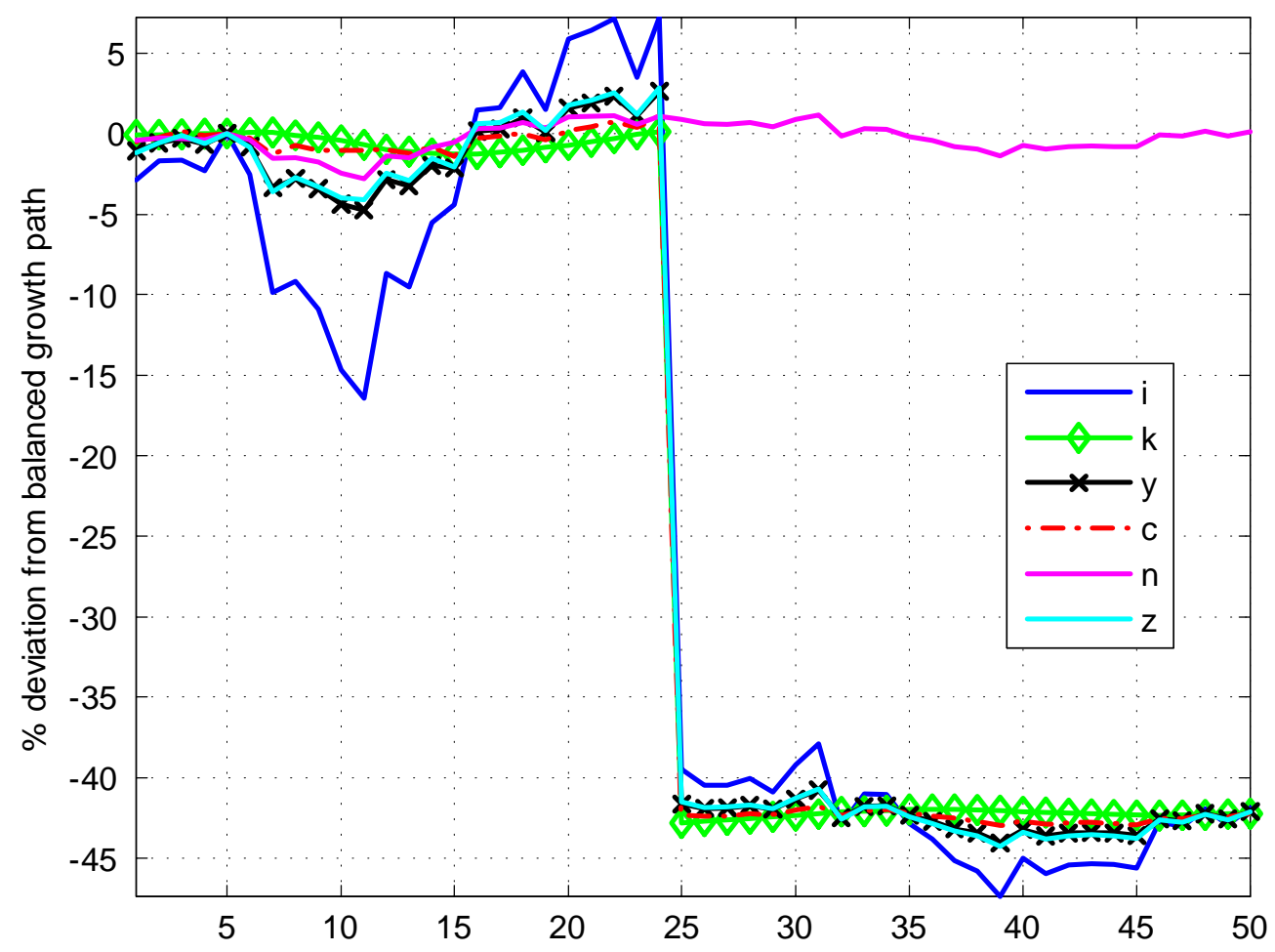

Figure 5: A sample path for macroeconomic quantities. Macroeconomic variables (I,K,N,Y,C) and TFP (Z) are driven by normal shocks, shocks to the probability of disaster, and realization of disasters (in this sample, there is one disaster at $t=25$ ). 

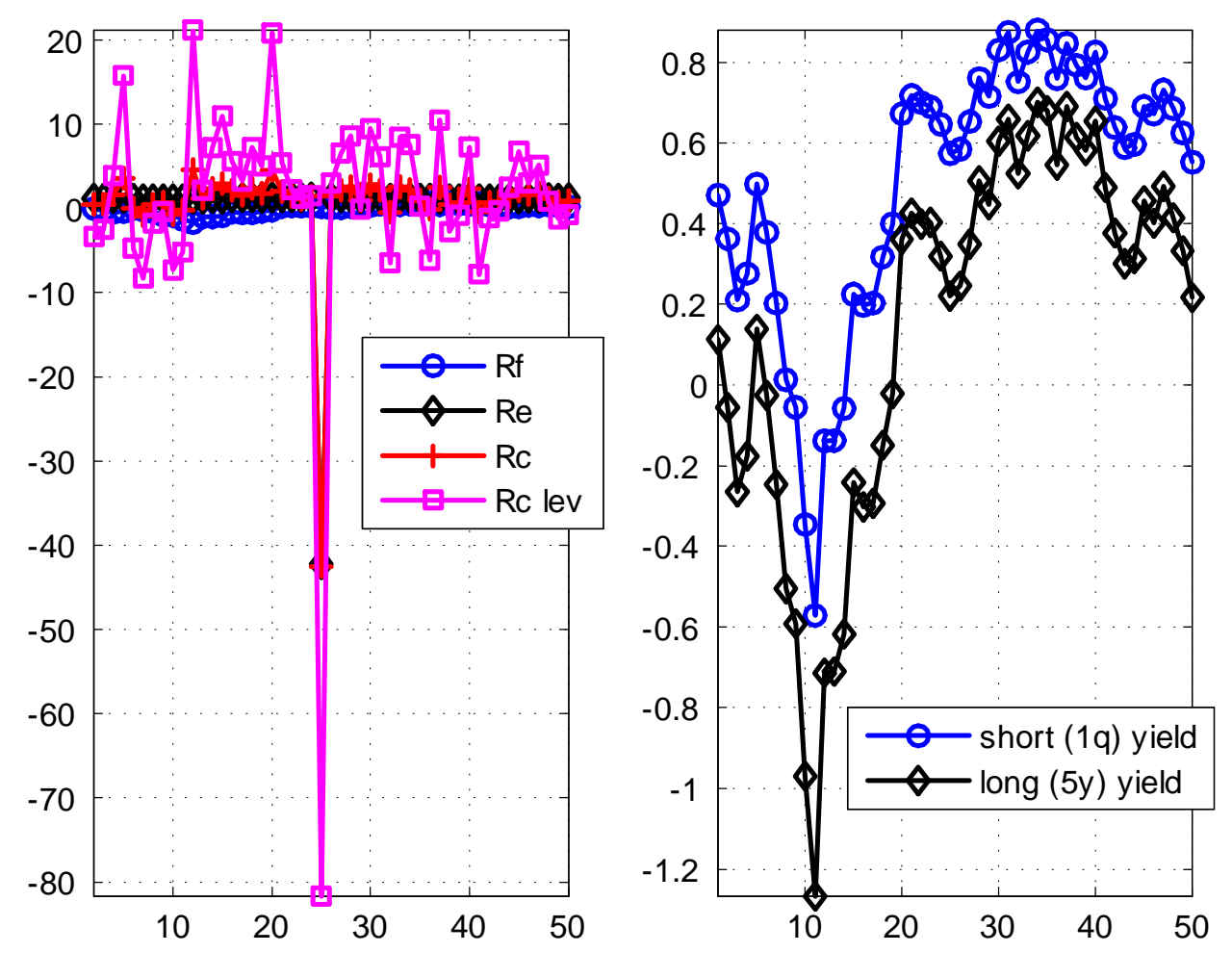

Figure 6: A sample path for asset returns. The left panel displays the returns on a pure risk-free asset, an equity, a claim to consumption, and a leveraged claim to consumption; the right panel shows the spath for the short (1q) and long (5y) yields on government debt. 


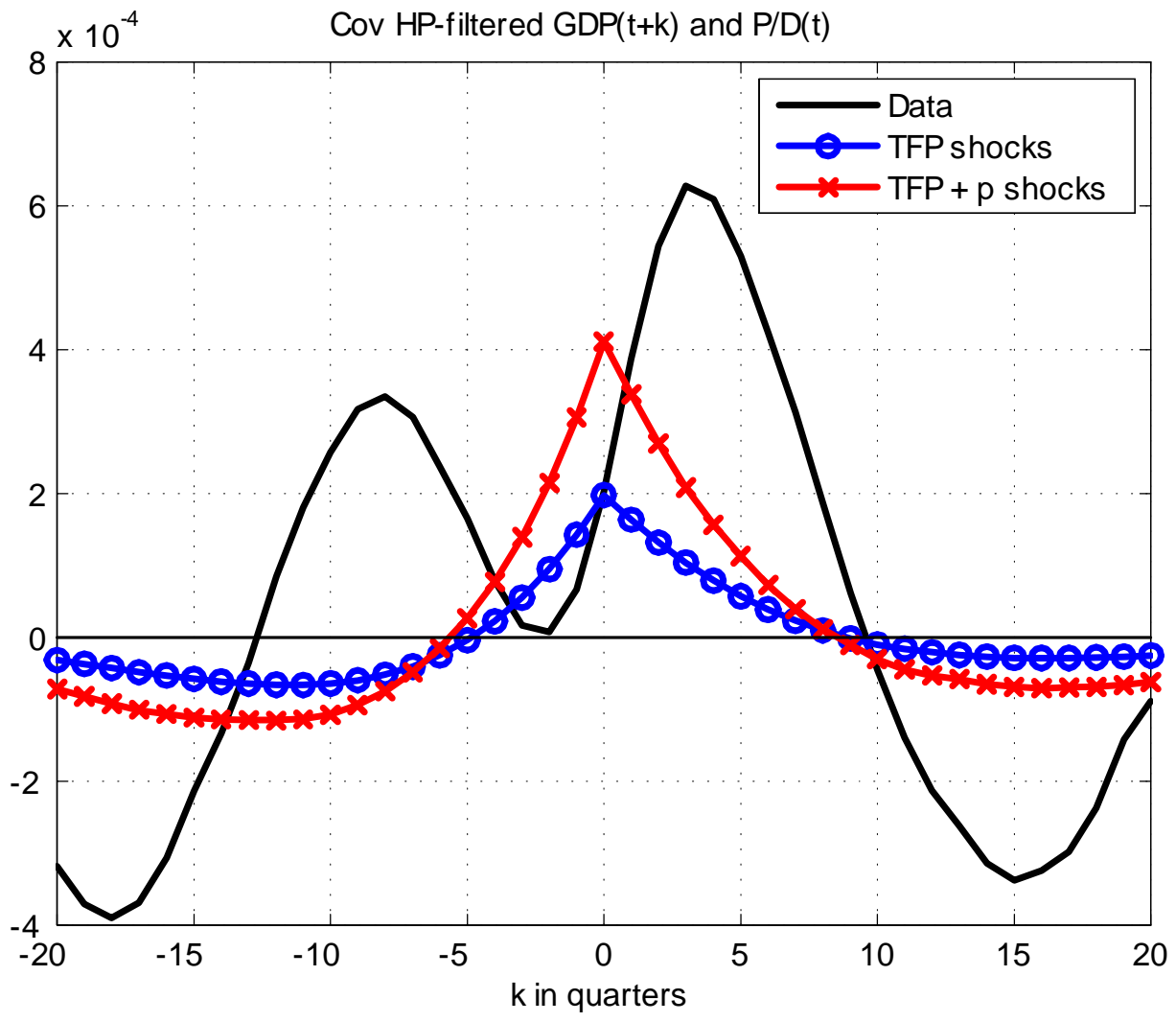

Figure 7: Relation between the stock market and GDP in the model and in the data. Crosscovariogram of the log P-D ratio and HP-filtered output, in the data (black, full line), the RBC model, i.e. the model with only TFP shocks, (blue line with circles) and the model with both p-shocks and TFP shocks (red line with crosses). 


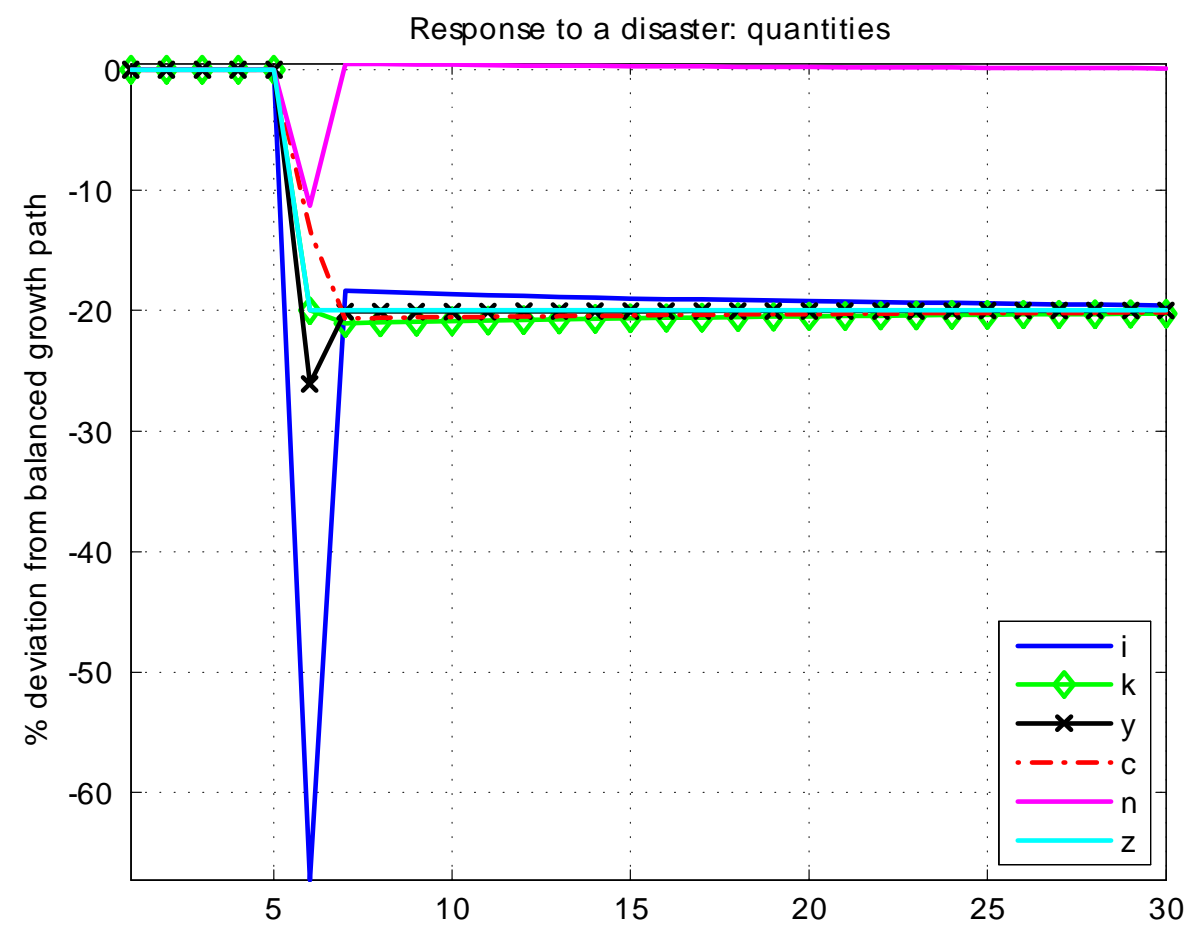

Figure 8: Impact of a disaster when disasters may last several periods. (Section 5.2) This picture plots a sample path for macroeconomic quantities where a $20 \%$ disaster occurs at $t=6$, and hence the probability of a further disaster rises to .5 . 